\title{
Subprime Mortgages and the Housing Bubble
}

\author{
$\mathrm{by}^{\dagger}$ \\ Jan K. Brueckner \\ Department of Economics \\ University of California, Irvine \\ 3151 Social Science Plaza \\ Irvine, CA 92697 \\ e-mail: jkbrueck@uci.edu \\ Paul S. Calem \\ Board of Governors of the Federal Reserve System \\ Washington, D.C. 20551 \\ e-mail:Paul.Calem@frb.gov \\ and \\ Leonard I. Nakamura \\ Federal Reserve Bank of Philadelphia \\ 10 Independence Mall \\ Philadelphia PA 19106 \\ e-mail: Leonard.Nakamura@phil.frb.org
}

February 2011, revised September 2011

\begin{abstract}
This paper explores the link between the house-price expectations of mortgage lenders and the extent of subprime lending. It argues that bubble conditions in the housing market are likely to spur subprime lending, with favorable price expectations easing the default concerns of lenders and thus increasing their willingness to extend loans to risky borrowers. Since the demand created by subprime lending feeds back onto house prices, such lending also helps to fuel an emerging housing bubble. These ideas are illustrated in a theoretical model, and tentative support is found in empirical work exploring the connection between price expectations and the extent of subprime lending.

$\dagger$ The views expressed in this paper are those of the authors and do not necessarily reflect those of the Federal Reserve Bank of Philadelphia, the Federal Reserve Board of Governors, or the Federal Reserve System. This paper is available free of charge at http://www.philadelphiafed.org/ research-and-data/publications/working-papers./
\end{abstract}




\title{
Subprime Mortgages and the Housing Bubble
}

by

\author{
Jan K. Brueckner, Paul S. Calem, and Leonard I. Nakamura*
}

\section{Introduction}

The spectacular run-up and subsequent collapse of US housing prices over the early years of the new century are watershed events in real-estate history, and they were accompanied by widespread use of subprime and non-traditional mortgages. No previous brief period witnessed such dramatic price escalation (on the order of 50 percent), and the rapid 30 percent price drop that ensued was also unprecedented.

Researchers have expended considerable effort in trying to understand these events, but our understanding thus far is incomplete. Previous research has largely focused on assessing the role of market fundamentals in house-price escalation and on exploring the link between credit supply and prices. The existing literature mostly views the growth of subprime credit as a possible cause of house-price escalation. But the present paper argues that an expansion of subprime lending may also be a consequence of price growth. The argument is that a favorable shift in lenders' house-price expectations, which may follow from past price appreciation, spurs subprime lending by easing default concerns. The resulting increase in the demand for housing then feeds back into the market, driving up today's housing prices. Expectations of future price growth can therefore generate in increase in current prices by boosting the supply of credit, feeding a housing "bubble." The paper thus argues that subprime lending is both a consequence and a cause of bubble conditions in the housing market. For present purposes, a bubble is defined as a rapid run-up in prices not linked to fundamentals.

These ideas are first developed in a detailed theoretical model. The paper then presents empirical work that searches for evidence of a link between price expectations and subprime lending, with the results giving suggestive, though by no means definitive, support for this hypothesis. To put these contributions in perspective, note first that previous studies have found little role for market fundamentals in explaining the run-up in house prices. See, for 
example, Glaeser, Gottlieb and Gyourko (2010), Coleman, LaCour-Little and Vandell (2008), and Wheaton and Nechayev (2008). Wheaton and Nechayev (2008) and Pavlov and Wachter (2011) do find evidence of an association between higher house prices and easing of mortgage credit standards, but since this connection does not materialize in other work, the extent to which price escalation is explained by the supply of credit remains unclear. ${ }^{1}$ Other papers, however, suggest a reverse causal link between prices and subprime lending like the one explored in this paper. Coleman, LaCour-Little and Vandell (2008) find evidence of a weakening connection between market fundamentals and house prices after 2003, concluding that price momentum had generated a "bubble" psychology where market participants grew to expect continuing price increases, weakening the perceived risks of subprime lending. ${ }^{2}$ Goetzman, Peng, and Yen (2011) present direct evidence of such a reverse link. They find a positive impact of past house-price appreciation (viewed as a proxy for price expectations) on the supply of subprime mortgage credit, as measured by loan approval rates and loan-to-income ratios. Dell'Ariccia, Igan and Laeven (2008) carry out a similar exercise. ${ }^{3}$ Mian and Sufi (2009), on the other hand, provide an indirect test for an expectations effect. Their approach compares price growth in areas ripe for subprime lending (zip codes with low household credit scores in 1996) to price growth in non-subprime zip codes, focusing on areas with elastic housing supply. They find no difference price escalation between these areas, concluding that the faster expansion of mortgage credit in subprime areas could not have been driven solely by (rational) price expectations. ${ }^{4}$

The theoretical model developed below provides a framework for understanding how subprime lending is both a consequence and a cause of house-price escalation. In the model, subprime lending is portrayed as an extension of credit to borrowers with low "default costs." These costs represent the penalty incurred by a borrower who defaults on a mortgage, which include the cost of credit impairment, moving costs, and any costs associated with guilt. Subprime borrowers presumably have low default costs since default will not greatly worsen a credit standing that is already bad. Although a previous paper by Brueckner (2000) analyzed mortgage lending when default costs are private information, the present analysis assumes that these costs (denoted $C$ ) are observable. The model generates a minimum value of $C$ 
below which mortgage lenders cannot profitably offer a mortgage, and market-level changes that reduce this minimum will generate an expansion in subprime lending.

One such change is a shift in lender expectations regarding future house prices. With a more optimist view of future prices, default is less of a concern for lenders, allowing them to extend mortgages to borrowers with even lower $C$ 's, thus leading to an expansion of subprime lending. While the basic analysis in section 2 below makes this point, an extension of the model allows the expansion of lending to feed back onto current house prices, bidding them up. Section 3 of the paper goes further by embedding the model in an explicitly dynamic setting, where a shift in expectations lasting only one period generates a long intertemporal adjustment process.

Relative to existing work, the paper's empirical contributions are its reliance on a direct measure of high-risk lending (borrower credit scores) and attention to potential simultaneity issues that arise in the econometric framework. The empirical work uses the Consumer Credit Panel database from the Federal Reserve Bank of New York, aggregated up to the state level for 2001 through 2008. The borrower-quality measure is the credit "risk score," which is analogous to the more familiar FICO score, being a measure of the borrower's creditworthiness. The dependent variable in the regressions is a state-level risk-score measure, equal to the mean risk score for new borrowers in the state or, alternatively, the 10th or 25th percentile of the state's risk-score distribution. The key explanatory variable, which is intended to capture price expectations, is the lagged annual rate of house-price appreciation, also used by Goetzmann et al. (2011) and Dell'Arricia et al. (2008). This variable relies on the state-level CoreLogic price index. The regressions include additional covariates as well as state and quarter fixed effects.

While the regression is meant to test for the causal path running from price expectations to subprime lending, the reverse path (by which subprime lending causes price escalation) is a potential source of simultaneity bias. Steps are taken to deal with this bias, although the remedy may be incomplete. The empirical results, presented in section 4 of the paper, thus provide suggestive, though not definitive, evidence for a causal link between prior price appreciation and subprime lending at the state level. ${ }^{5}$ 


\section{The Model}

\subsection{The setup}

The model, which draws on the framework of Brueckner (2000), is simple and stylized along a number of dimensions. The first simplifying assumption is that the mortgage term consists of two periods, an assumption that eliminates the option aspect of the mortgage default decision, as discussed further below. The borrower arranges a loan to purchase a standardized house of value $P_{0}$, and without loss of generality, the mortgage is assumed to be a 100 percent loan, so that the amount borrowed equals $P_{0}$. Repayment is required in the subsequent period. The balance-due, denoted $B$, includes the principal $P_{0}$ as well as interest, with the interest rate $r$ implicitly defined by $1+r=B / P_{0}$.

The value of the house in the next period is denoted $P$. Since $P$ may be lower than $P_{0}$, with the house value falling over the period, the borrower may default on the mortgage. Default occurs when $P$ is low relative to $B$, in which case the borrower is better off surrendering the house to the lender via foreclosure rather than paying off the mortgage. The resulting loss of the low-valued housing asset is more than offset by cancellation of a larger liability.

The critical value of $P$, below which default occurs, depends on the magnitude of default costs. These costs, denoted $C$, include the cost of credit impairment, moving costs, and any psychic costs from failing to honor the mortgage contract, as noted above. ${ }^{6}$ The role of default costs, which are sometimes called transaction costs, has been analyzed previously by Kau, Keenan and Kim (1993, 1994), Riddiough and Thompson (1993), Brueckner (2000), Foote, Gerardi, and Willen (2008) and others. In the model, default costs are heterogeneous across borrowers, ranging from a minimum value $\underline{C}$ to a maximum value of $\bar{C}$.

The magnitude of some elements of $C$, and thus the outcome of the default decision, can be affected by "trigger events," as discussed by Foote, Gerardi, and Willen (2008). ${ }^{7}$ Thus, default costs provide a way in which trigger events can play a role in a model that retains the spirit of the home-equity approach to default decisions.

Taking account of default costs, the borrower defaults on the mortgage when $P$ satisfies

$$
P-B<-C \text {. }
$$


$P-B$ in (1) equals housing equity, which is retained by the borrower if he repays the mortgage and thus represents the (possibly negative) increment to wealth in the absence of default. Conversely, $-C$ in (1) gives the (negative) increment to wealth if default occurs. Therefore, wealth is larger with default when housing equity is less than $-C<0$. Note that the presence of default costs implies that equity must fall well below zero before default is desirable. Rearranging, (1) shows that default is optimal when

$$
P<B-C
$$

Thus, default occurs when the house price is less than the mortgage balance-due less default costs.

In contrast to the analysis of Brueckner (2000), where default costs are private information, the current model assumes that $C$ is observable. In reality, the borrower's credit rating appears to give a good picture of the default propensity, with $C$ small (and default more likely) when the credit score is low. The model assumes that there are no other unobserved influences on $C$, which is perfectly proxied by the credit score.

With default costs thus observable, the lender tailors the mortgage contract offered to the borrower to reflect the observed value of $C$. Competition among lenders ensures that the resulting contract generates zero lender profit.

Computation of profit involves a key element: lender expectations regarding the next period's house prices, which help determine the perceived likelihood of default. Expectations are represented by the continuous density function $f(P)$, which is the same for all lenders. Generally, the density $f$ will depend on the entire past history of house prices, which will affect both the mean and variance of the distribution of anticipated prices, perhaps through a Bayesian updating process. The basic analysis that follows, however, does not require a description of exactly how expectations are formed. Instead, the main focus is on the effect of an exogenous shift in expectations, conditional on a general form for $f$. The formation of expectations must be specified, however, when the goal is to analyze the intertemporal adjustment process generated by an expectations shift, as seen in section 3 below. 
Suppose the lender is risk neutral, focusing on expected profit, and that he incurs a mortgage origination cost of $k$ for each loan issued. Then, incorporating $f$ and letting $\eta<1$ denote the lender's discount factor, the expected present value of profit from offering a loan with a balance-due of $B$ to a borrower with default $\operatorname{costs} C$ is given by

$$
\pi \equiv-k-P_{0}+\eta \int_{0}^{B-C} P f(P) d P+\eta \int_{B-C}^{\infty} B f(P) d P .
$$

Note that the lender transfers $P_{0}$ to the borrower when the loan is made. In the next period, he receives the loan balance $B$ from the borrower over the range of house values where $P \geq B-C$ holds and default does not occur. He takes possession of the house through foreclosure, earning $P$ from resale of the property, over the range of values where $P<B-C$ and default does occur. Without loss of generality, the foreclosure costs incurred by the lender are assumed to be zero. ${ }^{8}$

Although this formulation portrays the lender as using his own money to extend the loan, the analysis would be unaffected if he relied instead on borrowed funds (bank deposits). Then the outlay of $P_{0}$ would disappear from (3), being replaced by the discounted next-period interest payment $-\eta z P_{0}$, where $z$ is the lender's cost of funds. The model could also include a secondary market for mortgages. In this case, the secondary-market investor (the loan purchaser) would play the role of the lender.

The zero-profit condition for lenders requires that $\pi$ in (3) equals zero. The resulting equation then implicitly defines a value of $B$ that yields zero expected profit for a given value of $C$. Recalling that $1+r=B / P_{0}$, the equation also implicitly defines the interest rate that generates zero profit from lending to a borrower with the given default costs.

Before deriving the relation between $B$ and $C$, it is important to reiterate that the model's assumption of a two-period mortgage term eliminates the option aspect of the mortgage default decision, which is the subject of a vast literature. For example, if the mortgage term were three periods instead of two, then borrowers facing a low $P$ in the second period could either default at that point or else wait for a possible housing-market recovery in the third period. Incorporating this waiting choice (adding an option aspect to default) would require a much 
more complicated analysis but would not qualitatively change the implications of the model. ${ }^{9}$ The option approach would still generate a default rule like (2), although the possibility of a house-price recovery would make consumers more reluctant to default, requiring a lower $P$ to do so. The modified default rule would then be an input into the next section's analysis of the connection between $B$ and $C$, and the qualitative conclusions would be unaffected, as would much of the remaining analysis. Therefore, the options approach would leave the main lessons of the analysis unchanged while introducing greater complexity.

\subsection{The relation between $B$ and $C$}

Setting (3) equal to zero and totally differentiating, the effect of $C$ on $B$ is given by

$$
\frac{\partial B}{\partial C}=-\frac{\pi_{C}}{\pi_{B}}
$$

where $\pi_{C}$ and $\pi_{B}$ are the derivatives of $\pi$ with respect to these variables. Using Leibniz's rule,

$$
\pi_{C}=\eta[B f(B-C)-(B-C) f(B-C)]=\eta C f(B-C)>0 .
$$

By making default less likely for a given $B$, higher default costs thus raise profit.

Similarly, the effect of $B$ on profit is given by

$$
\pi_{B}=\eta\left[\int_{B-C}^{\infty} f(P) d P-C f(B-C)\right]
$$

where the first term comes from differentiating under the integral in (1). The sign of (6) is ambiguous as a result of two opposing effects. First, an increase in $B$ raises the lender's revenue in the event that default does not occur, an effect captured by the first term in brackets. However, an increase in $B$ makes default more likely, which has the opposite effect and leads to the negative second term in (6). One would expect the positive effect to dominate the second one, so that a larger balance-due raises expected profit. This outcome, for example, is guaranteed in the case where $f$ is uniform and given by $1 /(\bar{P}-\underline{P})$ over the support $[\underline{P}, \bar{P}]$, 
provided that an additional assumption holds. In this case,

$$
\pi_{B}=\eta \frac{\bar{P}-B}{\bar{P}-\underline{P}},
$$

which is positive under the assumption that the lender does not ask the borrower to pay back more than the maximal anticipated next-period house price $(B<\bar{P})$. More generally, with a unimodal $f$, it can be shown that $\pi_{B}$ is positive provided that the density is not too steep over its descending range.

Assuming that $\pi_{B}>0$, (4) is then negative, implying $\partial B / \partial C<0$. Thus, an increase in $C$ allows a reduction in $B$, with the lender setting the balance-due lower, or equivalently charging a lower interest rate, for a better quality borrower (one with a higher $C$ ). Since such a borrower is less likely to default, the amount $B$ that the bank recovers when default does not occur can be set lower. Therefore, a curve relating $B$ to $C$ is downward sloping over the relevant range, as shown in Figure $1 .^{10}$

That range is limited at the upper end by $\bar{C}$, the maximal value of default costs. A key additional assumption puts a lower limit on $C$. This assumption realistically imposes an upper bound on $B$ via a stylized form of the mortgage payment-to-income constraint. Such a constraint has been a key feature of mortgage underwriting for decades, although income requirements were substantially loosened for subprime borrowers in recent years.

To see the effect of the payment-to-income constraint, note that the mortgage payment is a component of $B$, being equal to $r P_{0}=B-P_{0}$. Assuming that borrower incomes are uniform and equal to $y$ despite heterogeneous default costs, the payment-to-income constraint is written $r P_{0} / y \leq \alpha$ for some constant $\alpha<1$. Substituting, the constraint becomes $\left(B-P_{0}\right) / y \leq \alpha$, or

$$
B \leq \alpha y+P_{0} \equiv \widehat{B}
$$

Let the value of $C$ associated with $\widehat{B}$ in Figure 1 be denoted $\widehat{C}$. Then, referring to the figure, the $B \leq \widehat{B}$ requirement implies $C \geq \widehat{C}$, so that an upper limit on the balance-due puts a floor of $\widehat{C}$ under allowable default costs. The reason is that, in lending to a borrower with 
default costs below $\widehat{C}$, zero profit would require a balance-due above the limit fixed by the payment-to-income constraint. Thus, mortgages cannot be offered to borrowers of less than a certain quality, those with $C$ values lying below $\widehat{C}$. As seen in Figure $1, \underline{C}$ is assumed to be less than $\widehat{C}$, so that low-quality potential borrowers in the range $[\underline{C}, \widehat{C}]$ cannot get a mortgage. ${ }^{11}$

The discussion so far has implicitly assumed that borrowers will always accept an offered mortgage, regardless of the magnitude of the balance-due. In effect, (owner-occupied) housing is assumed to be essential, so that a mortgage will be accepted regardless of its cost. Thus, the demand for mortgage funds is perfectly inelastic.

\subsection{Subprime lending}

In the model, subprime lending corresponds to a reduction in $\widehat{C}$. In other words, subprime lending gives some low-quality potential borrowers, who previously could not get a loan, access to mortgage funds. Parametric changes in the model can generate a reduction in $\widehat{C}$ and thus the emergence of subprime lending. Three changes in particular are of interest. The first is a relaxation of the payment-to-income constraint, as has occurred in recent years. The second change is a decline in the cost of lending, perhaps reflecting efficiency gains from greater reliance on the Internet. The third change, which is the main focus of the analysis, is a favorable shift in the lender's house-price expectations.

To analyze the effects of these changes, the explicit condition that determines $\widehat{C}$ is needed. This condition comes from setting $\pi$ from (3) equal to zero, and then substituting $\widehat{B}$ in place of $B$. The resulting condition determines the associated $C$ value, namely $\widehat{C}$, and it is written

$$
-k-P_{0}+\eta \int_{0}^{\widehat{B}-\widehat{C}} \operatorname{Pf}(P, \delta) d P+\eta \int_{\widehat{B}-\widehat{C}}^{\infty} \widehat{B} f(P, \delta) d P=0
$$

In (9), $\delta$ is a shift parameter for the house-price density. It is assumed that an increase in $\delta$ shifts the density toward higher values in the sense of stochastic dominance. In other words, with an increase in $\delta$, the cumulative distribution function shifts downward at each value of $P$ within the support of $f$. Thus, the $\delta$ derivative of $F(P, \delta) \equiv \int_{0}^{P} f(z, \delta) d z$ satisfies $F_{\delta}(P, \delta)<0$ over this support, where the subscript denotes partial derivative. 
Using (9), the effect on $\widehat{C}$ of an increase in $\alpha$, the maximum payment-to-income ratio, is easily derived. Totally differentiating (9) with respect to $\alpha$ and $\widehat{C}$, recognizing that $\alpha$ determines $\widehat{B}$ via (8), yields

$$
\frac{\partial \widehat{C}}{\partial \alpha}=-\frac{\pi_{B}(\partial \widehat{B} / \partial \alpha)}{\pi_{C}}<0
$$

where the inequality follows because $\pi_{C}>0, \pi_{B}$ is assumed positive, and $\partial \widehat{B} / \partial \alpha>0$ from (8). Thus, by raising the maximum possible $B$, relaxation of the payment-to-income constraint lowers the floor on $C$, allowing $\widehat{C}$ to fall and spurring subprime lending. In other words, by allowing lenders to recoup a larger balance-due when default does not occur, a higher $\alpha$ allows lenders to extend mortgages to borrowers of even lower quality without incurring a loss.

Similarly, since $\pi_{k}=-1$, it follows that $\partial \widehat{C} / \partial k=1 / \pi_{C}>0$. Thus, by raising profit, a decline in mortgage-origination costs allows lenders to extend loans to lower-quality borrowers.

The effect on $\widehat{C}$ of a shift in the lender's house-price expectations requires more extensive computation. The appendix shows that an increase in $\delta$ raises $\pi$ holding $\widehat{C}$ fixed, with

$$
\pi_{\delta}=-\eta\left[C F_{\delta}(\widehat{B}-\widehat{C}, \delta)+\int_{0}^{\widehat{B}-\widehat{C}} F_{\delta}(P, \delta) d P\right]>0
$$

Therefore, differentiating (9),

$$
\frac{\partial \widehat{C}}{\partial \delta}=-\frac{\pi_{\delta}}{\pi_{C}}<0
$$

A favorable shift in the house-price density thus leads to a reduction in $\widehat{C}$, with more optimistic price expectations spurring subprime lending. With better expectations, the perceived likelihood of default declines, other things equal, allowing loans to be extended to even lower-quality borrowers without generating a loss for the lender.

Recognizing that a shift in expectations is characteristic of a housing bubble, the results in (10) and (12) are summarized as follows:

Proposition 1. A favorable shift in the density of anticipated future house prices (as occurs under a housing bubble) spurs subprime lending, with the caliber of the 
lowest-quality borrower falling. This effect is reinforced by a relaxation of the paymentto-income constraint or a decline in mortgage-origination costs.

\subsection{Endogenizing $P_{0}$}

So far, the initial house price $P_{0}$ has been viewed as fixed despite the increase in the number of home buyers that follows from a decline in $\widehat{C}$. A full analysis, however, should allow $P_{0}$ to be endogenous, so that it can change along with $\widehat{C}$ in response to changes in the model's parameters. The size of houses, however, remains fixed at some standardized value.

To carry out this extension, the first step is to relate the number of demanders of housing to $\widehat{C}$. Let $G(C)$ denote the cumulative distribution function for default costs over the $[\underline{C}, \bar{C}]$ range, with $G(\underline{C})=0$ and $G(\bar{C})=N$, the number of potential mortgage borrowers. Then, the

number of housing demanders as a function of $\widehat{C}$ is simply $N-G(\widehat{C})$, which gives the number of individuals with $C$ values large enough to get a mortgage.

On the supply side, let $S\left(P_{0}\right)$ denote the supply function for new houses, which gives the number of houses supplied as an increasing function of price. Supply is assumed to be imperfectly elastic, so that $S^{\prime}\left(P_{0}\right)<\infty$. Note that housing production is assumed to be instantaneous, so that producers have no need to consider prices outside of the current period. Taking account of the supply function, the number of houses available would then equal the stock passed on from the previous period, denoted $H$, plus $S\left(P_{0}\right)$. The condition that equates housing supply and demand is then

$$
\Phi \equiv H+S\left(P_{0}\right)-[N-G(\widehat{C})]=0
$$

While a high price generates an increase in the number of houses, so that $S\left(P_{0}\right)>0$ holds for large values of $P_{0}$, units are removed from the housing stock when $P_{0}$ is low. This outcome reflects the existence of some alternate use for the housing land input, which is superior when housing commands a low price. Thus, the supply function satisfies $S\left(P_{0}\right)>(<) 0$ when $P_{0}>(<) P^{*}$, with $P^{*}$ giving the price where supply is zero.

The second equilibrium condition, which is based on (9), links $P_{0}$ and $\widehat{C}$ from the lender's side. The required modification comes from (8), which makes $\widehat{B}$ a function of the now- 
endogenous $P_{0}$ instead of simply a constant. This function is $\widehat{B}\left(P_{0}\right) \equiv \alpha y+P_{0}$, and it shows a positive relationship between $\widehat{B}$ and $P_{0} \cdot{ }^{12}$ Substituting $\widehat{B}\left(P_{0}\right)$ in place of $\widehat{B}$ in $(9)$, the condition is rewritten as

$$
-k-P_{0}+\eta \int_{0}^{\widehat{B}\left(P_{0}\right)-\widehat{C}} \operatorname{Pf}(P, \delta) d P+\eta \int_{\widehat{B}\left(P_{0}\right)-\widehat{C}}^{\infty} \widehat{B}\left(P_{0}\right) f(P, \delta) d P=0
$$

Conditions (13) and (14) jointly determine equilibrium values of $\widehat{C}$ and $P_{0}$.

The effect on these equilibrium values of a shift in house-price expectations can be analyzed diagrammatically. The equilibrium is the intersection of two locii in $\left(\widehat{C}, P_{0}\right)$ space, with one given by (13) and the other by (14). The locus given by (13), denoted the "supply-demand $(s-d)$ locus," is downward sloping. Totally differentiating (13), the slope of the locus is given by

$$
\left.\frac{\partial P_{0}}{\partial \widehat{C}}\right|_{s-d}=-\frac{\Phi_{\widehat{C}}}{\Phi_{P_{0}}}=-\frac{G^{\prime}(\widehat{C})}{S^{\prime}\left(P_{0}\right)}<0
$$

where the sign follows from $G^{\prime}, S^{\prime}>0$.

The locus given by $(14)$, denoted the " $\pi$ locus," is upward sloping. Its slope is given by

$$
{\frac{\partial P_{0}}{\partial \widehat{C}_{\left.\right|_{\pi}}}}=-\frac{\pi_{C}}{\pi_{P_{0}}}=\frac{-\pi_{C}}{\pi_{B}\left(\partial \widehat{B} / \partial P_{0}\right)-1}>0
$$

Given $\pi_{C}>0$, the inequality in (16) is a consequence of the negativity of the last denominator expression, which is easily demonstrated. ${ }^{13}$

Figure 2 illustrates the $s-d$ and $\pi$ locii and their intersection. When house-price expectations shift, with $\delta$ increasing, the $\pi$ locus shifts, while the $s$ - $d$ locus (which is independent of $\delta$ ) remains fixed. The shift in the $\pi$ locus is leftward in the $\widehat{C}$ direction, as shown in the figure. This conclusion follows given that $\partial \widehat{C} /\left.\partial \delta\right|_{\pi}<0$ holds from (12), which indicates that $\widehat{C}$ falls as $\delta$ increases, holding $P_{0}$ fixed. As seen in Figure 2, this shift in the $\pi$ locus reduces the equilibrium value of $\widehat{C}$ while raising $P_{0}$.

Since (10) shows that the $\pi$ locus again shifts to the left when $\alpha$ increases, a relaxation of the payment-to-income constraint has the same impacts on $\widehat{C}$ and $P_{0}$ as a shift in expectations. These same effects also arise when origination costs $k$ decline. Summarizing yields. 
Proposition 2. When the current house price $P_{0}$ is endogenous, a rightward shift in the density of anticipated future prices (as occurs under a housing bubble) raises $P_{0}$ while again spurring subprime lending, with the caliber of the lowest-quality borrower falling. A relaxation of the payment-to-income constraint or a decline in mortgage origination costs reinforces these effects.

Thus, growth in subprime lending continues to be a consequence of a shift in future houseprice expectations, a relaxation of the payment-to-income constraint or a decline in mortgageorigination costs. In addition, all three changes feed back onto current prices, making houses more expensive. Note, however, that if housing supply is perfectly elastic, with $S^{\prime}\left(P_{0}\right)$ infinite, then the slope expression in (15) equals zero. The $s$ - $d$ locus is then flat, so that an expectations shift has no price impact (see Figure 2). ${ }^{14}$

\subsection{Eventual default}

The actual default decisions of borrowers occur in the subsequent period, and they depend on the house price that emerges in that period. To analyze default, the realized value of $P$ must be inserted into the default condition (2) along with the balance due $B$ owed by a given borrower, which is shown by the curve in Figure 1. To write the balance-due as a function of the relevant variables, let (3) be rewritten to include the shift parameter $\delta$. Then, setting (3) equal to zero, the condition determines $B$ as a function of $C$ and the other variables $P_{0}$ and $\delta$, written as $B=\phi\left(C, P_{0}, \delta\right)$. This function is decreasing in $C$, as seen above, and it is also increasing in $P_{0}$ and decreasing in $\delta .^{15}$

Let $\widetilde{C}$ denote the critical value of $C$ that makes a borrower indifferent in the subsequent period between defaulting and not doing so. Referring to (2), $\widetilde{C}$ satisfies

$$
P=\phi\left(\widetilde{C}, P_{0}, \delta\right)-\widetilde{C}
$$

Since $\phi$ is decreasing in $C$, it follows that $\phi\left(C, P_{0}, \delta\right)-C$ is also decreasing in $C$, which means that $P<\phi\left(C, P_{0}, \delta\right)-C$ holds for $C<\widetilde{C}$. Thus, after taking account of $B$ 's dependence on $C$, actual defaulters are those borrowers with the lowest default costs.

For future reference, note that (17) determines the critical value $\widetilde{C}$ as function of the remaining variables in the equation. This function, which is written $\widetilde{C}\left(P, P_{0}, \delta\right)$, is decreasing 
in $P$ given that a larger realized house value makes a borrower less prone to default, requiring $C$ to fall below a lower critical value to make default desirable. In addition, since a larger $P_{0}$ raises $B$, higher default costs are required to forestall default, so that $\widetilde{C}$ is increasing in $P_{0}$. Finally, since a higher $\delta$ reduces the required $B$, lower default costs are required to induce default, making $\widetilde{C}$ a decreasing function of $\delta .{ }^{16}$

While this discussion is silent about how the realized $P$ value is determined, this omission is remedied below when the model is embedded in a dynamic setting.

\section{Making the Model Dynamic: An Example}

While the paper's empirical work relies only on Proposition 2, further insight can be gained by using the model to carry out a dynamic analysis. In a dynamic setting, a one-time shift in house-price expectations leads to an intemporal adjustment process. Analysis of this process can give insight into the evolution of housing and mortgage markets in the presence of a housing bubble.

The first step is to attach a time index $t$ to $P_{0}$ and $\widehat{C}$, which are now written $P_{0}^{t}$ and $\widehat{C}^{t}$. The realized house price in the period following $t$ then equals the $P_{0}$ value for that period, or $P_{0}^{t+1}$. The next step is to specify exactly how the lender's house-price expectations are formed, a question that could be skirted in the analysis up to this point. While the expectations density $f$ will depend on the entire past history of house prices, as mentioned above, this dependence is assumed to take a very simple form in order to permit a tractable analysis. Given this limitation, the ensuing discussion should be viewed as only providing an example of how the model might behave in a dynamic setting.

The simplifying assumption is that the position of the density of anticipated prices depends on the previous period's house price, with a change in that price shifting the density without changing its shape. Thus, the time- $t$ density for the next period's anticipated price is written $f\left(P-P_{0}^{t-1}\right)$, so that a given increase in $P_{0}^{t-1}$ shifts the density to the right by the amount of the increase. ${ }^{17}$ This assumption could correspond, for example, to a situation where $f$ is

symmetric and centered at $P_{0}^{t-1}$, so that a change in $P_{0}^{t-1}$ alters the mean of the distribution while its variance is independent of the past history. In addition, a change in expectations, as 
reflected in an increase in $\delta$, is assumed to shift the density in the same way as the past price, so that when $\delta$ is nonzero, the density is written as $f\left(P-P_{0}^{t-1}-\delta\right)$.

Incorporating these changes, the zero-profit condition (14) at time $t$ is rewritten as

$-k-P_{0}^{t}+\eta \int_{0}^{\widehat{B}\left(P_{0}^{t}\right)-\widehat{C}^{t}} \operatorname{Pf}\left(P-P_{0}^{t-1}-\delta\right) d P+\eta \int_{\widehat{B}\left(P_{0}^{t}\right)-\widehat{C}^{t}}^{\infty} \widehat{B}\left(P_{0}^{t}\right) f\left(P-P_{0}^{t-1}-\delta\right) d P=0$.

To adapt the supply-demand condition in (13) to a dynamic setting, recall that $H$ in (13) is the number of housing units inherited from the previous period. Assuming that housing is perfectly durable (unless intentionally removed from the stock), $H$ simply equals the number of mortgage borrowers in the previous period. Therefore, (13) at time $t$ becomes

$$
N-G\left(\widehat{C}^{t-1}\right)+S\left(P_{0}^{t}\right)-\left[N-G\left(\widehat{C}^{t}\right)\right]=0
$$

Finally, the dynamic setup involves a particular assumption on the fate of borrowers who default on their mortgages. ${ }^{18}$

Since $P_{0}^{t-1}$ enters (18), the position of the $\pi$ locus relating $P_{0}^{t}$ and $\widehat{C}^{t}$ depends on $P_{0}^{t-1}$. An increase in $P_{0}^{t-1}$ shifts that locus to the left, just like the increase in $\delta$ analyzed above. Similarly, the position of the $s$-d locus depends on $\widehat{C}^{t-1}$, with an increase in $\widehat{C}^{t-1}$ shifting the locus to the right. ${ }^{19}$ Note that, with a higher $\widehat{C}^{t-1}$, a smaller housing stock is handed forward from time $t-1$, so that supply-demand equilibrium at $t$ requires fewer current mortgage borrowers (a higher $\widehat{C}^{t}$ ) for any given $P_{0}^{t}$.

Conditions (18) and (19) constitute a system of difference equations that governs the evolution of the $\widehat{C}$ and $P_{0}$ variables over time. Suppose the economy is in a steady state up to time $\tau-1$. The steady-state price equals the zero-supply price $P^{*}$, and the steady-state $\widehat{C}$ is denoted $\widehat{C}^{*} \cdot{ }^{20}$ Then, suppose that the equilibrium is perturbed at time $\tau$ by a shift in house-price expectations, with $\delta$ becoming positive. The $\pi$ locus shifts as in Figure 2 , with $P$ rising and $\widehat{C}$ falling at time $\tau$, as shown again in Figure 3. The equilibrium moves from the steady-state values $P^{*}$ and $\widehat{C}^{*}$, which lie at the intersection of the steady-state $\pi^{*}$ and $s$ - $d^{*}$ locii, to the values at the intersection of $\pi^{\tau}$ and $s-d^{*}$ locii. 
At time $\tau+1$, the expectations shock is past, with $\delta$ returning to zero. But the time- $\tau$ changes in $P$ and $\widehat{C}$ affect the positions of the $\pi$ and $s$-d locii at $\tau+1$, following the above discussion. Since $\widehat{C}^{\tau+1}<\widehat{C}^{*}$, the $s$ - $d$ locus at time $\tau+1$ lies to the left of the steady-state locus, as seen in Figure 3. To locate the $\pi^{\tau+1}$ locus, it can be shown that the house price at time $\tau$ does not rise by the full amount of the expectations shift, so that $P_{0}^{\tau}<P^{*}+\delta .^{21}$ As a result, the $\pi$ locus at $\tau+1$ (whose position depends on $P_{0}^{\tau}$ ) is not as far to the left as the $\pi^{\tau}$ locus (whose position depends on $P^{*}+\delta$ ), as shown in Figure 3. Given these two shifts, it follows that the house price at $\tau+1$ must be lower than at $\tau$, with $P_{0}^{\tau+1}<P_{0}^{\tau}$. Depending on the exact positions of the curves, $\widehat{C}$ could either rise or fall between times $\tau$ and $\tau+1$, with Figure 3 showing the latter case. ${ }^{22}$

This information can be used to investigate the time path of defaults. Letting $\widetilde{C}^{t}$ denote, for time $t$, the critical $\widetilde{C}$ value below which default occurs, the default rate at $t$ is given by

$$
D^{t}=\frac{G\left(\widetilde{C}^{t}\right)-G\left(\widehat{C}^{t-1}\right)}{N-G\left(\widehat{C}^{t-1}\right)} .
$$

The denominator equals the number of consumers getting mortgages at $t-1$ (whose $C$ values lie above $\widehat{C}^{t-1}$ ) and the numerator equals the number of these individuals who default at $t$ (whose $C$ values lies above $\widehat{C}^{t-1}$ and below $\widetilde{C}^{t}$ ). At time $\tau-1$, the $G$ arguments in (20) equal the starred, steady-state values, yielding the steady-state default rate $D^{*}$.

The increase in the house price at $\tau$ reduces the incentive for default, pushing the critical $\widetilde{C}$ value below the steady-state level, so that $\widetilde{C}^{\tau}<\widetilde{C}^{*}{ }^{23}$ Since $\widehat{C}^{\tau-1}$ equals the steady value $\widehat{C}^{*}$, it follows from (20) that the default rate declines at time $\tau$, with $D^{\tau}<D^{*}$.

In moving from time $\tau$ to $\tau+1$, the default rate is affected by changes in both $\widetilde{C}$ and the lagged $\widehat{C}$. Differentiation of (20) shows $D^{t}$ rises when $\widehat{C}^{t-1}$ decreases, so that an expansion in subprime lending raises the subsequent default rate, holding $\widetilde{C}$ fixed. ${ }^{24}$ Thus, the decline in the lagged $\widehat{C}$ from $\widehat{C}^{\tau-1}=\widehat{C}^{*}$ to $\widehat{C}^{\tau}<\widehat{C}^{*}$ tends to increase the default rate between times $\tau$ and $\tau+1$. However, the change in $\widetilde{C}$ between these periods is ambiguous. ${ }^{25}$ Although the drop in $P_{0}$ raises the incentive to default, which tends to increase $\widetilde{C}$, the higher past price and the previous period's expectation shift have opposing effects on the balance-due owed at time 
$\tau+1$, which makes the direction of change in $\widetilde{C}$ unclear. However, if the $\widehat{C}$ effect dominates, the default rate will rise. Summarizing yields

Proposition 3. Under the maintained assumptions, a house-price expectations shift at time $\tau$ raises the current house price $P_{0}$ above the steady-state level while reducing the default rate $D$ at $\tau$ relative to its own steady-state level. In the subsequent period $(\tau+1)$, the house price falls relative to the level at time $\tau$. The change in the default rate is ambiguous, but a large expansion in subprime lending at $\tau$ will tend to make it positive.

The ambiguity regarding $D^{\tau+1}$ as well as the evolution beyond time $\tau+1$ can be explored numerically. The calculations assume that the density $f$ at time $t$ is uniform, with height $1 / 2 \mu$ over the interval $[\underline{P}, \bar{P}]=\left[P_{0}^{t-1}+\delta-\mu, P_{0}^{t-1}+\delta+\mu\right]$. In addition, default costs are uniformly distributed, and the supply function is linear.

Under the parameter values listed in the appendix, $P^{*}=5.0$ and $\widehat{C}^{*}=2.2$. At time $\tau, P_{0}$ rises to 5.36 and $\widehat{C}$ falls dramatically to 0.67 , as seen in Figure 4 . From a steady-state value of 1.7 percent, the default rate at time $\tau$ drops to zero, as seen in Figure 5 . At time $\tau+1, P_{0}$ falls almost all the way back to the steady-state value, dropping to 5.01, while $\widehat{C}$ declines further to 0.57 (matching Figure 3). The previous period's expansion of subprime lending dominates in determining the change in the default rate, which surges to 40 percent at time $\tau+1$, a number that approximates actual experience. ${ }^{26}$ At time $\tau+2$, the house price drops below the steady-state level while $\widehat{C}$ rises almost back to $\widehat{C}^{*}$, indicating a drop in subprime lending. The default rate declines only slightly. ${ }^{27}$

The subsequent evolution of $P_{0}$ and $\widehat{C}$ is depicted in Figure 4, which shows convergence back to the steady state. ${ }^{28}$ Close inspection of the adjustment paths shows that they exhibit the cyclical convergence seen in Figure 3, an outcome that is robust to variations in the underlying parameter values. Figure 5 shows that the default rate also convergences cyclically back to its steady-state value, spending several periods at zero before returning to $D^{*}$.

Given the analytical and simulation results, several observations can be made about the intertemporal path generated by the shock to house-price expectations. In response to the initial shock, subprime lending surges as $\widehat{C}$ declines, and the resulting increase in demand pushes up the current house price and enlarges the housing stock. While this price increase 
partly sustains favorable price expectations for the subsequent period, the optimism is weaker than under the initial shock. This fact (captured in the $\pi$ locus's rightward shift), together with the larger housing stock handed forward from time $\tau$ (reflected in the $s$ - $d$ locus's leftward shift), pushes down the housing price at time $\tau+1$. This drop, along with the presence of new low- $C$ borrowers, leads to a spike in defaults. As the adjustment process continues, subprime lending

eventually abates, with $P_{0}, \widehat{C}$ and the default rate ultimately returning to their steady-state values. $^{29}$

\section{Empirical Evidence}

\subsection{Data}

The discussion now turns to a description of the empirical work motivated by Proposition 2. Credit risk scores, drawn from the New York Fed's Consumer Credit Panel database, are used to measure the extent of subprime lending in a state. The database is a 5 percent sample of the entire US credit-bureau population (individuals with credit information), taken as a panel, with the same set of social security numbers drawn each quarter. The risk-score measures are scaled like the FICO scores that are also commonly used as a criterion for mortgage lending (the sample score range is from 280 to 850). In the data, the borrower's risk score is tabulated when a new mortgage is originated in a given quarter. Risk scores are then aggregated by state for each quarter, with the state's mean score, the 10th percentile score, and the 25th percentile score computed. The sample covers the 32 quarters running from 2001Q1 to 2008Q4.

The sample of borrowers is split into repeat home buyers, refinancers, investors and firsttime buyers. A repeat buyer is a borrower who had a previously recorded mortgage and changed address upon receiving the new mortgage. A refinancer is a borrower with a previously recorded mortgage who did not change address in the quarter before or the two quarters after receiving the new mortgage. An investor is a borrower who had two additional first-lien mortgages with positive balances when the new mortgage was received.

Identification of first-time home buyers is less straightforward than for these other categories. A first-time buyer is a borrower who did not have a recorded mortgage in the prior four quarters, who was 40 years old or younger, and whose oldest account still active (as recorded by 
the credit bureau) was less than or equal to 240 months from its time of origination. Although some households could have paid off an unobserved previous mortgage well before borrowing again, thus looking like first-time buyers, the restriction to households no older than 40 with credit histories shorter than 20 years lessens the chance of such misidentification, since few borrowers with these characteristics could have paid off a previous mortgage. Another potential problem is that some prior mortgages may not be recorded in credit-bureau records, although in recent years this oversight is likely to be uncommon.

Additional variables include quarterly state house price indexes from CoreLogic, quarterly state unemployment rates from the Bureau of Labor Statistics, and the Conference Board's quarterly regional Consumer Confidence Index for the nine U.S. Census regions. Another variable is real quarterly state personal income, constructed by Haver Analytics from state personal income data deflated using the PCE chained price index, both from the Bureau of Economic Analysis. These latter three variables, which were downloaded from Haver DLX databases, control for demand-side effects, including the possibility that the risk composition of borrowers varies with the economic cycle. ${ }^{30}$

\subsection{Empirical framework}

Empirical work exploring the connection between lender price expectations and subprime lending must confront two challenges. First, how are price expectations to be measured? Second, given that subprime lending feeds back onto house prices, with a possible effect on price expectations themselves, how can the causal effect of expectations on lending be isolated?

The first challenge is met by using past price appreciation as a proxy for lender expectations regarding future prices. When past appreciation is rapid, lenders are assumed to expect higher future prices than when past appreciation is moderate. Recall that the model of section 3 assumed that the location of the density of anticipated house prices depended on the level of the previous period's price (with an expectations shock shifting the density in the same way as an increase in the past price). By assuming that rapid past price appreciation, rather than a high past price level, produces favorable expectations for the future price, the empirical work takes a different, more realistic approach. Note that in this setting, an expectations shock and an exogenous increase in past appreciation would have equivalent effects. Observe 
also that the empirical work does not provide an internal test of the assumption that lenders extrapolate past appreciation forward in predicting future house prices. But such behavior seems reasonable, and it is supported by indirect evidence. ${ }^{31}$

Before discussing the second challenge (feedback from subprime lending to house prices), it is useful to consider preliminary empirical results that do not seriously address it. Once these results have been digested, the simultaneity problem is explored in more detail. The empirical model, which captures the connection between subprime lending and price expectations, relates the aggregate risk-score measure in state $j$ in quarter $t$, denoted $R I S K S C O R E_{j t}$, to the oneyear (4-quarter) lag of annual house-price appreciation, denoted $H P I C H G_{j t-4}$. This variable is computed as $\left(H P I_{j t-4}-H P I_{j t-8}\right) / H P I_{j t-8}$, where $H P I$ is house-price index. Faster past appreciation is expected to reduce the risk-score measure, indicating an expansion of subprime lending. Note that by using the lagged appreciation rate, rather than an appreciation rate ending at the current quarter (which may be affected by contemporaneous lending), the simultaneity problem is lessened. As seen below, however, this approach does not eliminate it.

The regression equation is

$$
R I S K S C O R E_{j t}=\beta_{0}+\beta_{1} H P I C H G_{j t-4}+\beta_{2} X_{j t}+\epsilon_{j t}
$$

where $\epsilon_{j t}$ is an error term and $\beta_{1}$ is negative. $X_{j t}$ is a vector of additional covariates that also help determine $R I S K S C O R E_{j t}$. These variables include the state unemployment rate for the given quarter $\left(U N R_{j t}\right)$, per capita income $\left(P C_{j t}\right)$, and the regional consumer confidence index $\left(C C_{j t}\right)$. Also included in $X_{j t}$ are state fixed effects, captured by a vector $S$ of state dummy variables that equals $S_{j}$ for state $j$, and quarterly fixed effects, captured by a vector $T$ of quarter dummy variables that equals $T_{t}$ for quarter $t .^{32}$

By capturing economic well-being at the household level, $U N R_{j t}$ and $P C_{j t}$ help determine borrower creditworthiness and thus individual risk scores, so that their presumed effects on the aggregate measure are respectively negative and positive. ${ }^{33}$ The consumer-confidence variable may help determine lender optimism about the future, while also capturing economic well-being. Under the first interpretation, an increase in $C C_{j t}$ should lead to a reduction 
in the aggregate risk-score measure as lenders serve riskier borrowers, but under the second interpretation, the effect of $C C_{j t}$ could be positive. Table 1 shows the summary statistics for the variables used in the model and gives their definitions. One noteworthy comparison is that each of the three RISKSCORE measures for first-time buyers is lower than the corresponding measure for the other borrower groups.

Borrower risk scores and prior house-price appreciation may be linked for a reason different from the one envisioned in the model, and separate estimation of equation (21) for each of the four different borrower groups helps to distinguish between these linkages. To see the problem, note that rapid prior appreciation will raise the home equity of repeat buyers and refinancers, making a larger downpayment, and hence lower loan-to-value ratio, feasible on a new house purchase. The resulting reduction in default risk may in turn make lenders more willing to extend mortgages to borrowers with lower risk scores, generating an inverse relationship between prior appreciation and risk scores like that predicted by the model. This linkage, however, is not present for first-time buyers, who enjoy no wealth gain from prior appreciation. Therefore, the regression for first-time buyers provides a crucial way of distinguishing between these two sources of correlation between prior appreciation and borrower risk scores.

\subsection{Preliminary results}

Table 2 shows the preliminary regression results, where (21) is estimated by ordinary least squares. Three regressions are reported for each borrower group, with the mean, 10th and 25th percentile risk scores as dependent variables. In order to give bigger states (with their larger number of mortgage borrowers) more weight, (21) is estimated in weighted fashion, with quarterly observations for each state weighted by the average annual borrower count for the state. Significance tests are based on robust standard errors.

Except in the 10th percentile regression for first-time buyers, all the $\beta_{1}$ estimates in Table 2 are significantly negative at the 5 percent level or better, showing that higher past price appreciation reduces borrower risk scores. These results are consistent with Proposition 2, and the fact that significant estimates also emerge for the first-time borrowers discounts the housing-equity effect discussed above as the source of the findings. It should be noted that the weak 10th-percentile result for this group could be due to the very low risk-score range that 
this value represents (in the 500's, compared to the 600's for repeat buyers), which probably reflects low household incomes. With an increasingly binding payment-to-income constraint from higher house prices eroding affordability for this group, any effect of a relaxation of underwriting standards may be hard to detect.

The effects of the other covariates vary across borrower groups. The consumer confidence index has a significantly positive effect on the risk score for all groups except investors, suggesting that $C C_{t}$ is capturing current economic well-being, which generates high borrower risk scores, rather than proxying favorable lender expectations about the future, which would encourage lending to riskier borrowers. A higher per capita income raises risk scores in almost all cases for refinancers and first-time buyers, as expected, but the effects for the other groups are mostly insignificant. Unexpectedly, the unemployment rate has virtually no effect on borrower risk scores.

\subsection{An attempt to address the simultaneity problem}

As explained above, use of the lagged appreciation rate partly circumvents a simultaneity problem in the regression that would be present had annualized appreciation through the current quarter been used instead. In other words, whereas fast annual appreciation up to the current quarter could encourage subprime lending, the feedback effect from this lending would raise current house prices and thus the measured rate of appreciation through the current period. Price appreciation would then be affected by subprime lending as well as being a cause of it, precluding isolation of the expectations effect. However, since prices one year back cannot be affected by current subprime lending, use of the lagged appreciation rate helps address the simultaneity problem.

Nevertheless, a residual simultaneity effect may remain as a consequence of serial correlation in the error terms in (21). To understand this point, observe that the feedback effect from subprime lending to prices can be captured by an equation relating $H P I C H G_{j t-4}$ to $R I S K S C O R E_{j t-4}$ and additional covariates $Z_{j t-4}$, which is written

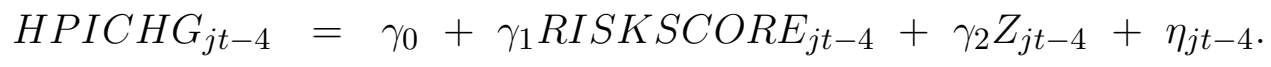


Note that since an expansion of subprime lending at quarter $t-4$ (a lower $R I S K S C O R E_{j t-4}$ ) raises price appreciation through that date by raising $t-4$ 's price, it follows that $\gamma_{1}<0$ holds. The $Z_{j t-4}$ vector could include the annual rates of changes in the $X$ variables $U N R, P C I$ and $C C$, all of which are shifters of housing demand, as well the annual rate of population change for the state. It is natural to assume that the error term $\eta$ in (22) is uncorrelated with $\epsilon$ from (21), with $\eta_{j r}$ and $\epsilon_{k s}$ being uncorrelated for any $r, s, j$ and $k$.

To see that serial correlation in the $\epsilon$ 's poses a threat to consistent estimation, let (21) be lagged four quarters to generate $R I S K S C O R E_{j t-4}$, with the result substituted into (22). After simplifying, the resulting equation can be written

$$
H P I C H G_{j t-4}=\theta_{0}+\theta_{1} H P I C H G_{j t-8}+\theta_{2} X_{j t-4}+\gamma_{2} Z_{j t-4}+\gamma_{1} \epsilon_{j t-4}+\eta_{j t-4},
$$

where $\theta_{1}=\gamma_{1} \beta_{1}$ and $\theta_{2}=\gamma_{1} \beta_{2}$. Because $H P I C H G_{j t-4}$ depends on $\epsilon_{j t-4}$ from (23), $H P I C H G_{j-4}$ in (21) will be correlated with the error term $\epsilon_{j t}$ if the $\epsilon^{\prime}$ s are themselves serially correlated. This correlation will in turn bias the OLS estimates of (21).

Serial correlation in the $\epsilon$ 's would arise through serial correlation in unobserved, timevarying determinants of the extent of subprime lending in a state. While the pattern of serial correlation could in principle be very complex, suppose that $\epsilon$ follows a simple annual AR process. In this case, $\epsilon_{j t}=\rho \epsilon_{j t-4}+v_{j t}$, where $\rho$ is the autoregressive parameter and the $v_{j t}$ are i.i.d. error terms. ${ }^{34}$ Successive substitution shows that $\epsilon_{j t}$ then depends on $v_{j t}, v_{j t-4}, v_{j t-8}, \ldots$

Under the AR1 assumption, an autoregressive tranformation yields an estimating equation purged of correlation between the covariates and the error term. Lagging (21) by four quarters, multiplying by $\rho$ and subtracting the result from (21) yields

$$
\begin{aligned}
\operatorname{RISKSCORE~}_{j t}= & (1-\rho) \beta_{0}+\rho R I S K S C O R E_{j t-4}+\beta_{1} H P I C H G_{j t-4} \\
& -\rho \beta_{1} H P I C H G_{j t-8}+\beta_{2} X_{j t}-\rho \beta_{2} X_{j t-4}+v_{j t}
\end{aligned}
$$

Since HPICHG depends on the contemporaneous $\epsilon$ from (23), it depends on the contemporaneous $v$ and all the earlier $v$ 's. As a result, $H P I C H G_{j t-4}$ and $H P I C H G_{j t-8}$ do not depend on 
$v$ 's later than $v_{j t-4}$, which means that these variables are independent of $v_{j t}$. Thus, (24) lacks the correlation between the covariates and the error term that prevents consistent estimation of (21).

If the error structure is more complex than the simple AR1 structure, the error term in an equation generated by an autoregressive transformation of (21) would involve additional terms, which may still be correlated with the right-hand variables. Recognizing this potential pitfall, it is nevertheless worthwhile estimating (24) under the assumption that the AR1 structure is correct. To estimate such a model, the usual approach would rely on the OLS residuals from (21) to estimate $\rho$, with the result substituted in (24) and the $\beta$ coefficients then estimated by OLS. However, since OLS estimation of (21) is inconsistent given the correlation between HPIC $\mathrm{HG}_{j-4}$ and the error term, the resulting estimate of $\rho$ is inconsistent as well. A different approach that circumvents this problem is to estimate (24) by nonlinear least squares.

\subsection{Additional results}

Nonlinear least squares estimates of (24) are presented in Tables 3-6, which separately show results for the different borrower groups. Results are also presented for the alternative case where (21) uses a two-quarter rather than four-quarter lag of annual house-price appreciation, $H P I C H G_{j t-2}=\left(H P I_{j t-2}-H P I_{j t-6}\right) / H P I_{j t-6}$ rather than $H P I C H G_{j t-4}$. The regressions are again weighted and rely on robust standard errors. ${ }^{35}$

Table 3 shows the nonlinear estimation results for repeat buyers. The second column, which uses the mean risk score and the same four-quarter lag as in Table 2, yields a significantly negative $\beta_{1}$ estimate and a significant $\rho$ estimate of about 0.2 . The $\beta_{1}$ coefficient is smaller in absolute value than in Table 2's OLS regression, suggesting that the estimate under OLS is downward biased. This conclusion in fact follows from the model, as can be seen by noting that the inverse relationship between $\mathrm{HPICHG}_{j-4}$ and $\epsilon_{j t-4}$ from $(23)$ (recall $\gamma_{1}<0$ ) means that a negative correlation exists between $H P I C H G_{j t-4}$ and the error term $\epsilon_{j t}$ in (21) (equal to $\left.\rho \epsilon_{j t-4}+v_{t}\right)$ when $\rho>0$, leading to downward bias in the OLS estimate of $\beta_{1}$.

The third column of the Table shows the regression results when the lag in (21) is two quarters rather than four, with $H P I C H G_{j t-4}$ replaced by $H P I C H G_{j t-2}$. The $\beta_{1}$ estimate remains significantly negative while falling in absolute value, and the $\rho$ estimate is now larger 
at 0.26 , a difference that makes sense given the shorter lag. The regressions shown in the remaining blocks of Table 2 use the 10th and 25th percentile risk scores as dependent variables, and the $\beta_{1}$ coefficients increase in absolute value relative to the mean-score regressions while remaining significantly negative. The estimated $\beta_{1}$ 's in the 4-quarter-lag regressions are again smaller in absolute value than the corresponding OLS estimates from Table $2 .{ }^{36}$

To gauge the quantitative implications of the results, note that the mean regressions in Table 3 imply that a 10 percentage-point increase in past annual house-price appreciation reduces the mean risk score among repeat buyers by about 4 points. According to the model, this reduction comes from a decrease in the minimum risk score $(\widehat{C})$ due to an expansion in subprime lending. Further analysis shows this drop in the lowest risk score will equal some multiple of the 4 -point decrease in the mean score. ${ }^{37}$ Thus, the results are consistent with an appreciable reduction in the risk score of the worst borrowers receiving mortgages in response to higher past price appreciation price.

Table 4 shows the results for the case of refinancers. All the $\beta_{1}$ coefficients are again significantly negative, with the magnitudes for the 4-quarter-lag case again smaller in absolute value than the corresponding OLS estimates from Table 2. The first-time buyer results are shown in Table 5 , and the $\beta_{1}$ estimates are again significantly negative when the dependent variable is the mean risk score or the 25 th percentile score. While the coefficient is insignificant when the dependent variable is the 10th percentile risk score (as in Table 2), the fact that the anticipated negative effect of the lagged HPICHG still emerges for first-time buyers near the bottom of the risk score distribution (at the 25th percentile) and at the mean tends to discount the alternate equity-based explanation for the results. Table 6 shows the regressions for investors, and the results once again show significantly negative $\beta_{1}$ coefficients. ${ }^{38}$ The estimated coefficients of the consumer confidence and income variables are again frequently positive and significant in the non-investor regressions, with an unemployment effect again mostly absent.

As mentioned in the introduction, Dell'Ariccia et al. (2008) and Goetzmann et al. (2011) estimate a model similar to (21). But instead of relying on a borrower risk-score measure, their dependent variable is the loan approval rate (or disapproval rate in the case of the first 
paper), measured at the MSA level. As is done here, Dell'Ariccia et al. (2008) use a panel data set over the period 2000-2006, with price appreciation lagged one year as the right-hand variable. By contrast, Goetzmann et al. (2011) rely on a cross-section regression for 2006, with price appreciation measured from 1999 through 2005. Although the approach of Dell'Ariccia et al. entails the same simultaneity problem confronted here (which they acknowledge), the problem is unaddressed. However, since Goetzmann et al. measure past appreciation over a longer period, simultaneity may be less of a concern in their work. The results of both papers match the present findings: rapid past price appreciation raises the loan approval rate (or reduces the disapproval rate).

\subsection{Discussion}

The results presented so far appear to offer support for the hypothesis that favorable lender price expectations can spur subprime lending. However, this conclusion hinges on the untested claim that past house-price appreciation is an appropriate expectations measure, and that a simple one-period lag of annual appreciation is the right variable (rather than, say, a distributed lag). In addition, the affirmative interpretation of the results requires some confidence that the paper's empirical procedures have at least partly surmounted a difficult endogeneity problem. If readers are willing to grant the first claim but lack the confidence in the efficacy of the empirical procedures, then additional empirical steps could be undertaken.

One approach would be to pursue an instrumental variables strategy for dealing with correlation between $H P I C H G_{j-4}$ and the error term in (21). Successive substitution in (23) shows that $H P I C H G_{t-4}$ depends on the values of the $X$ and $Z$ variables at time $t-4$ and earlier. In view of this structure, a possible IV approach would consist of regressing $H P I C H G$ on a series of lagged $X$ and $Z$ values and then using the fitted values in place of $H P I C H G_{t-4}$ in (21). However, since the dynamic setting means that the model does not fit into the usual two-stage-least-squares framework, the statistical properties of the resulting estimates are not entirely clear. ${ }^{39}$ But the results are similar to those in Tables $2-6$, with the $\beta_{1}$ estimates significantly negative for repeat buyers and refinancers and marginally significant for first-time buyers. This alternate approach may thus increase confidence that an expectations effect is truly present in the data. ${ }^{40}$ At a minimum, though, the paper's empirical results provide 
suggestive, though not necessarily definitive, evidence for the presence of such an effect, which is reinforced by the similar findings of Dell'Ariccia et al. (2008) and Goetzmann et al. (2011).

\section{Conclusion}

This paper has explored the link between the house-price expectations of mortgage lenders and the extent of subprime lending. It argues that bubble conditions in the housing market are likely to spur subprime lending, with favorable price expectations easing the default concerns of lenders and thus increasing their willingness to extend loans to risky borrowers. Since the demand created by this subprime lending feeds back onto house prices, the lending also helps to fuel an emerging housing bubble. The paper, however, focuses mostly on the reverse causal linkage, where subprime lending is a consequence rather than a cause of bubble conditions.

The paper's theoretical model portrays subprime lending as the extension of loans to risky borrowers with low observable "default costs," and the analysis demonstrates that a favorable shift in house-price expectations spurs such lending. By showing that borrower riskiness indeed

rises (risk scores fall) when a proxy for expectations (past price appreciation) becomes more favorable, the empirical work provides suggestive evidence that such an expectations effect may be at work. But further empirical research is clearly needed to supplement this evidence.

By providing formal theoretical grounding for a link between price expectations and subprime lending, and by offering a new empirical test, the paper advances our understanding of the housing crisis. A better understanding of this watershed economic event is crucial in formulating policies to prevent its repetition, and this paper may add some of the required insights. 


\section{Appendix}

Derivation of (12)

Integrating by parts, the profit expression in (9) can be rewritten as

$$
\begin{gathered}
-k-P_{0}+\eta\left((\widehat{B}-\widehat{C}) F(\widehat{B}-\widehat{C}, \delta)-\int_{0}^{\widehat{B}-\widehat{C}} F(P, \delta) d P+\widehat{B}[1-F(\widehat{B}-\widehat{C}, \delta)]\right)= \\
k-P_{0}-\eta\left[\widehat{C} F(\widehat{B}-\widehat{C}, \delta)+\int_{0}^{\widehat{B}-\widehat{C}} F(P, \delta) d P-\widehat{B}\right] .
\end{gathered}
$$

Differentiating (a1) with respect to $\delta$ yields (11).

\section{Simulation assumptions}

The height of the uniform default-cost density is $1 / g$, where $g=\bar{C}-\underline{C}$, and the cumulative distribution function in (19) is then $G(\widehat{C})=(\widehat{C}-\underline{C}) / g$ (the mass $N$ of potential mortgage borrowers is normalized to unity). Furthermore, with linear housing supply, $S\left(P_{0}^{t}\right) \equiv n P_{0}^{t}-k$, implying $P^{*}=k / n$. Given these latter assumptions, (19) reduces to

$$
\widehat{C}^{t}-\widehat{C}^{t-1}+g\left(n P_{0}^{t}-k\right)=0 .
$$

Letting $a \equiv \alpha y$, so that $B\left(P_{0}^{t}\right)=a+P_{0}^{t}$, and assuming $\eta=1$, (18) reduces to

$$
\left(\widehat{C}^{t}\right)^{2}-\left(a+P_{0}^{t}\right)^{2}+\left(P_{0}^{t-1}+\delta-\mu\right)\left[2\left(a+P_{0}^{t}\right)-\left(P_{0}^{t-1}+\delta-\mu\right)\right]+4 a \mu=0 .
$$

To carry out the simulation, $(a 2)$ is used to eliminate $\widehat{C}^{t}$ in $(a 3)$, so that $P_{0}^{t}$ can be written as a function of the prior values $P_{0}^{t-1}$ and $\widehat{C}^{t-1}$. With $P_{0}^{t}$ then known given these values, substitution in (a2) determines $\widehat{C}^{t}$ as a function of $P_{0}^{t-1}$ and $\widehat{C}^{t-1}$. The time paths shown in Figure 4 reflect the following additional parameter values: $a=2.28, \mu=4.5, k=10, n=2$ and $g=4$. Given the highly stylized nature of the model, real-world evidence was not relevant in the choice of parameter values. The values were selected to generate a simulation that best illustrates the properties of the model.

Under these parameter values, $B<\bar{P}$ holds at each point in time for all borrowers, so that $\pi_{B}$ in (7) is positive as assumed (note that $B-C<\bar{P}$ then also holds). In addition, assuming $\underline{C}=0$, the condition $B-C>\underline{P}$ is satisfied at each point in time for all borrowers.

To compute default rates, the uniformity assumption is imposed in (18) (lagged one period), and the condition is solved for $B$ to yield

$$
B=P_{0}^{t-2}+\mu+\delta-\left[C^{2}+4 \delta \mu-4 \mu P_{0}^{t-1}+4 \mu P_{0}^{t-2}\right]^{1 / 2}
$$

This solution with $C$ replaced by $\widetilde{C}$ is then substituted into the condition $P_{0}^{t}=B-\widetilde{C}$ to yield $\widetilde{C}$ as a function of $P_{0}^{t}, P_{0}^{t-1}, P_{0}^{t-2}$ and $\delta$. 


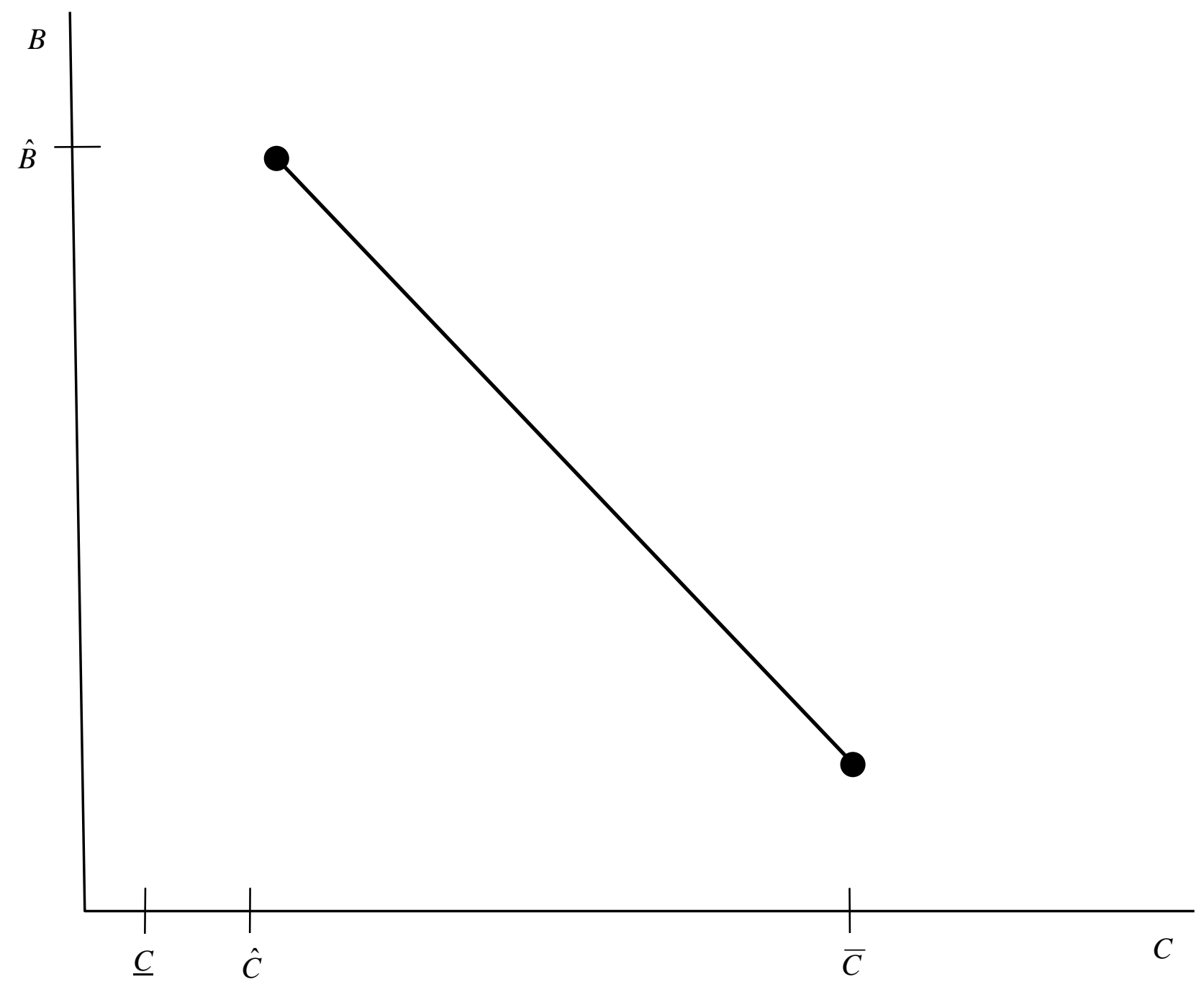

Figure 1: The relationship between $B$ and $C$ 


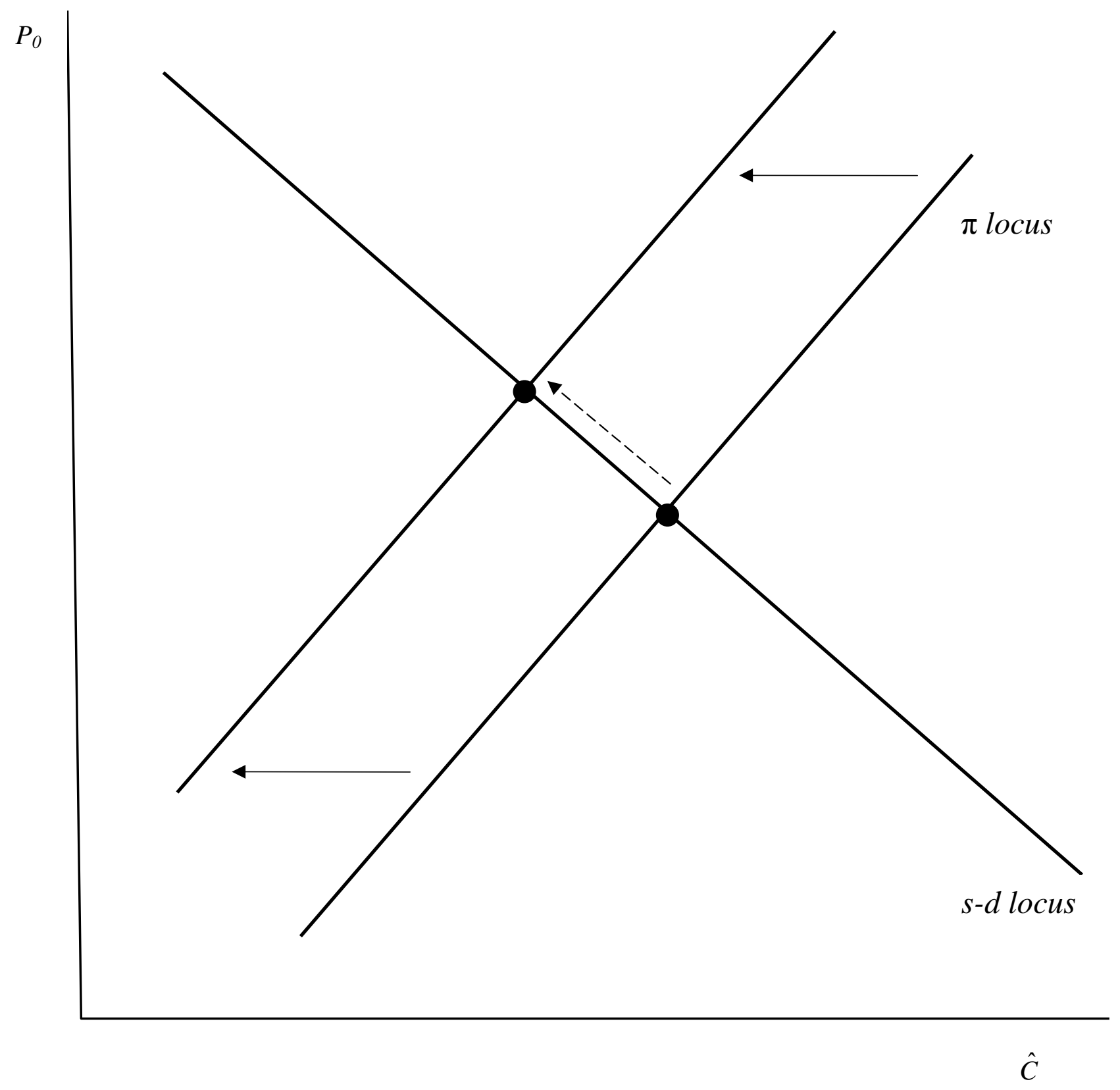

Figure 2: The effect of a shift in house-price expectations 


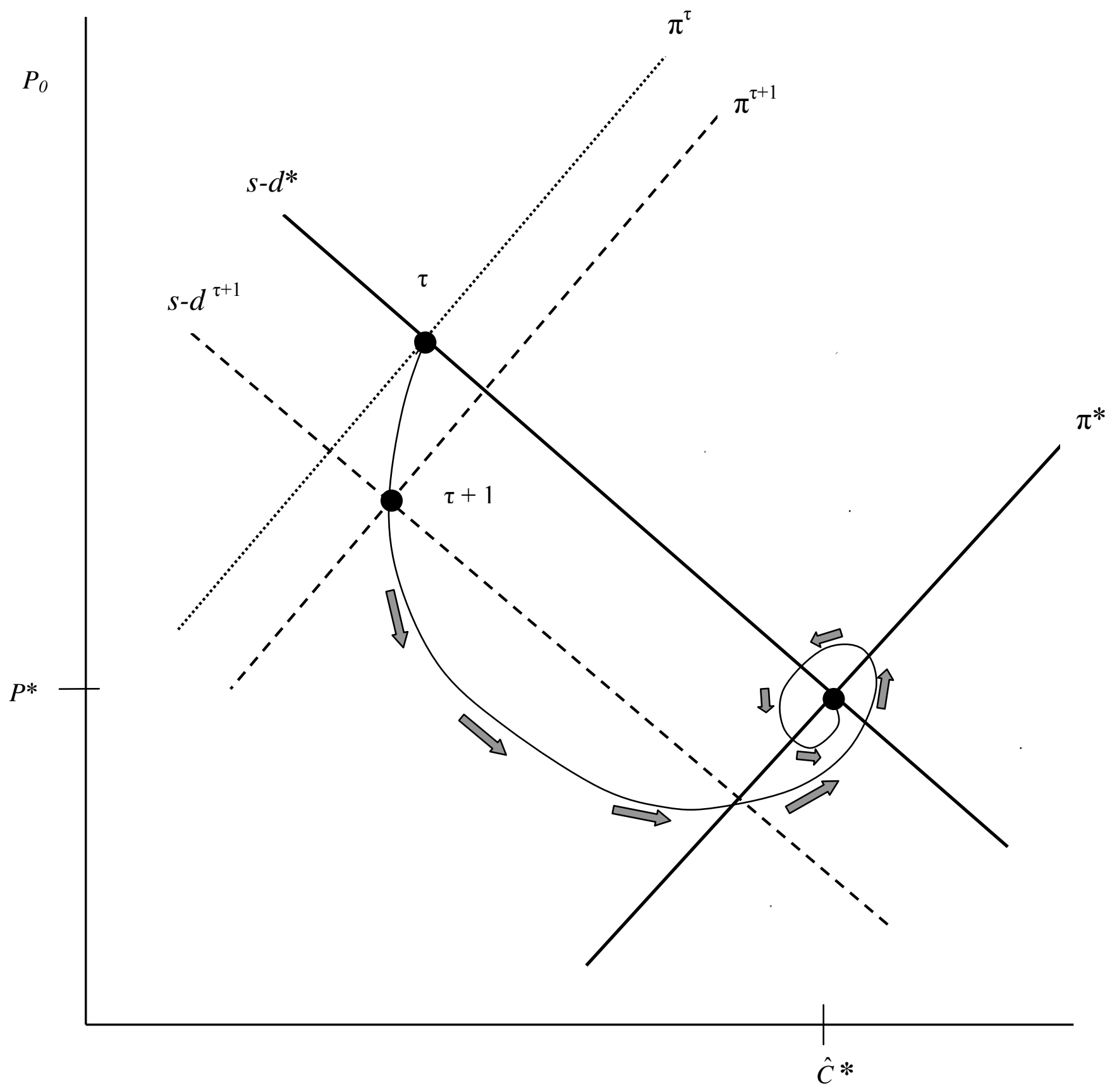

Figure 3: Adjustment to a house-price-expectation shock 


\section{Figure 4: Simulation Results}

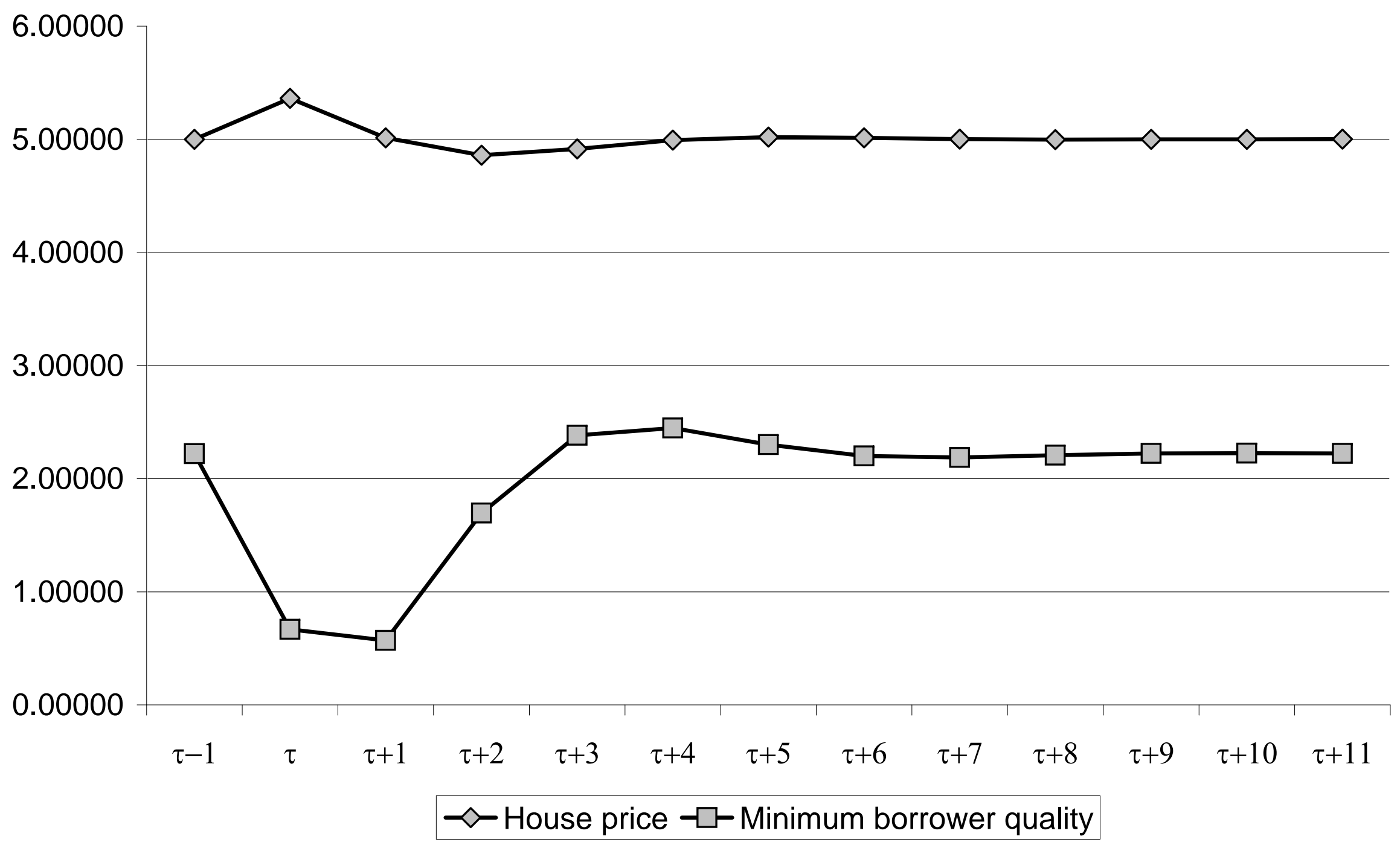


Figure 5: Default rate

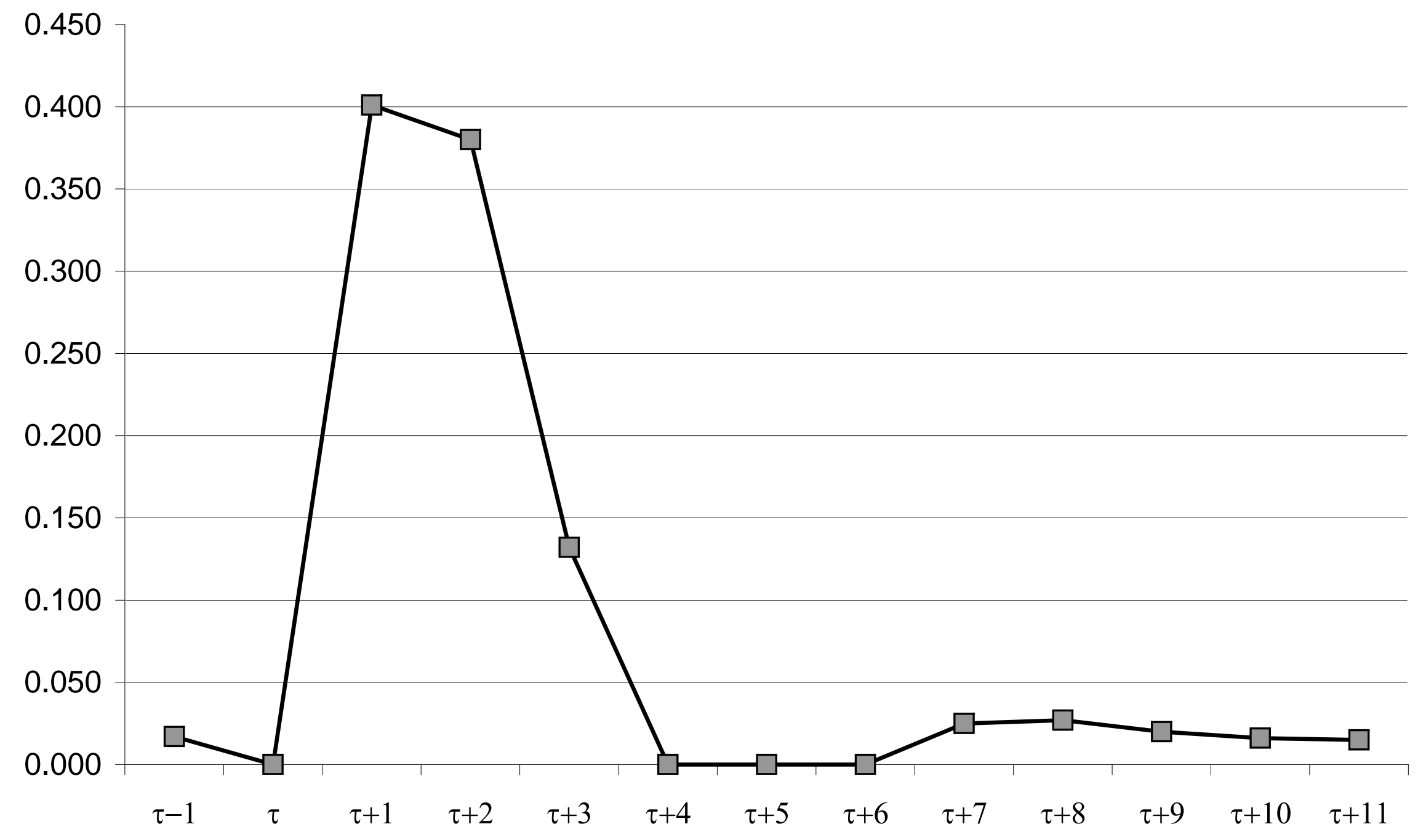




\begin{tabular}{|c|c|c|c|c|c|c|c|c|c|}
\hline & \multirow[b]{2}{*}{$\mathrm{N}$} & \multicolumn{2}{|c|}{ First time buyers } & \multicolumn{2}{|c|}{ Repeat buyers } & \multicolumn{2}{|c|}{ Refinancers } & \multicolumn{2}{|c|}{ Investors } \\
\hline & & Mean & SD & Mean & SD & Mean & SD & Mean & SD \\
\hline $\begin{array}{l}\text { Risk score - mean } \\
\text { RISKSCOREM }\end{array}$ & 1600 & 689.0 & 15.47 & 722.62 & 12.96 & 715.6 & 16.36 & 735.3 & 17.44 \\
\hline $\begin{array}{l}\text { Risk score }-10 \text { th percentile } \\
\text { RISKSCORE } 10\end{array}$ & 1600 & 585.4 & 20.52 & 627.66 & 20.89 & 610.4 & 25.61 & 649.0 & 29.39 \\
\hline $\begin{array}{l}\text { Risk score }-25 \text { th percentile } \\
\text { RISKSCORE } 25\end{array}$ & 1600 & 636.4 & 20.26 & 683.70 & 18.21 & 669.8 & 23.90 & 698.9 & 25.52 \\
\hline $\begin{array}{l}\text { Unemployment rate } \\
\text { UNR }\end{array}$ & 1600 & 4.92 & 1.17 & 4.92 & 1.17 & 4.92 & 1.17 & 4.92 & 1.17 \\
\hline $\begin{array}{l}\text { Consumer confidence ind. } \\
\text { CC }\end{array}$ & 1600 & 95.52 & 21.90 & 95.52 & 21.90 & 95.52 & 21.90 & 95.52 & 21.90 \\
\hline $\begin{array}{l}\text { State house price inflation } \\
\text { HPICHG }\end{array}$ & 1600 & 5.23 & 8.07 & 5.23 & 8.07 & 5.23 & 8.07 & 5.23 & 8.07 \\
\hline $\begin{array}{l}\text { Per capita income } \\
P C I\end{array}$ & 1600 & 35.25 & 11.54 & 35.25 & 11.54 & 35.25 & 11.54 & 35.25 & 11.54 \\
\hline
\end{tabular}




\begin{tabular}{|c|c|c|c|c|c|c|c|c|c|c|c|c|}
\hline & \multicolumn{3}{|c|}{ Repeat buyers } & \multicolumn{3}{|c|}{ Refinancers } & \multicolumn{3}{|c|}{ First-time buyers } & \multicolumn{3}{|c|}{ Investors } \\
\hline & Mean & $\begin{array}{c}10^{\text {th }} \\
\text { Percentile }\end{array}$ & $\begin{array}{c}25^{\text {th }} \\
\text { Percentile }\end{array}$ & Mean & $\begin{array}{c}10^{\text {th }} \\
\text { Percentile }\end{array}$ & $\begin{array}{c}25^{\text {th }} \\
\text { Percentile }\end{array}$ & Mean & $\begin{array}{c}10^{\text {th }} \\
\text { Percentile }\end{array}$ & $\begin{array}{c}25^{\text {th }} \\
\text { Percentile }\end{array}$ & Mean & $\begin{array}{c}10^{\text {th }} \\
\text { Percentile }\end{array}$ & $\begin{array}{c}25^{\text {th }} \\
\text { Percentile }\end{array}$ \\
\hline Constant & $\begin{array}{c}467.779 * * \\
(4.822)\end{array}$ & $\begin{array}{c}407.462 * * \\
(10.211)\end{array}$ & $\begin{array}{c}437.864 \\
(8.029)\end{array}$ & $\begin{array}{c}839.825 * * \\
(13.426)\end{array}$ & $\begin{array}{c}654.739 * * \\
(25.945)\end{array}$ & $\begin{array}{c}742.111 * * \\
(22.600)\end{array}$ & $\begin{array}{c}685.443 * * \\
(7.656)\end{array}$ & $\begin{array}{c}589.630 * * \\
(10.872)\end{array}$ & $\begin{array}{c}613.835 * * \\
(10.632)\end{array}$ & $\begin{array}{c}273.698^{* *} \\
(3.495)\end{array}$ & $\begin{array}{c}241.608^{* *} \\
(7.664)\end{array}$ & $\begin{array}{c}263.383^{* *} \\
(5.292)\end{array}$ \\
\hline $\begin{array}{l}H P I C H G_{t-4} \\
\left(\beta_{1}\right)\end{array}$ & $\begin{array}{c}-0.469 * * \\
(0.047)\end{array}$ & $\begin{array}{c}-0.647 * * \\
(0.087)\end{array}$ & $\begin{array}{c}-0.682 * * \\
(0.072)\end{array}$ & $\begin{array}{c}-0.631 * * \\
(0.084)\end{array}$ & $\begin{array}{c}-0.891 * * \\
(0.167)\end{array}$ & $\begin{array}{c}-0.916^{* *} \\
(0.146)\end{array}$ & $\begin{array}{c}-0.152 * * \\
(0.046)\end{array}$ & $\begin{array}{l}-0.085 \\
(0.059)\end{array}$ & $\begin{array}{c}-0.170 * \\
(0.067)\end{array}$ & $\begin{array}{c}-0.283 * * \\
(0.042)\end{array}$ & $\begin{array}{c}-0.556^{* *} \\
(0.101)\end{array}$ & $\begin{array}{c}-0.464 * * \\
(0.065)\end{array}$ \\
\hline$C C t$ & $\begin{array}{c}0.109 * * \\
(0.018)\end{array}$ & $\begin{array}{c}0.238 * * \\
(0.035)\end{array}$ & $\begin{array}{c}0.176 * * \\
(0.028)\end{array}$ & $\begin{array}{l}0.151 * * \\
(0.022)\end{array}$ & $\begin{array}{c}0.300 * * \\
(0.039)\end{array}$ & $\begin{array}{c}0.268 * * \\
(0.037)\end{array}$ & $\begin{array}{l}0.048 * \\
(0.020)\end{array}$ & $\begin{array}{c}0.0163^{* *} \\
(0.025)\end{array}$ & $\begin{array}{c}0.122 * * \\
(0.030)\end{array}$ & $\begin{array}{c}0.031 \\
(0.028)\end{array}$ & $\begin{array}{c}0.095 \\
(0.052)\end{array}$ & $\begin{array}{c}0.067 \\
(0.042)\end{array}$ \\
\hline UNRt & $\begin{array}{c}0.002 \\
(0.332)\end{array}$ & $\begin{array}{c}-0.910 \\
(0.657)\end{array}$ & $\begin{array}{l}-0.345 \\
(0.523)\end{array}$ & $\begin{array}{c}0.089 \\
(0.468)\end{array}$ & $\begin{array}{c}0.376 \\
(0.898)\end{array}$ & $\begin{array}{c}0.171 \\
(0.797)\end{array}$ & $\begin{array}{l}-0.487 \\
(0.274)\end{array}$ & $\begin{array}{c}0.060 \\
(0.383)\end{array}$ & $\begin{array}{c}-0.611 \\
(0.366)\end{array}$ & $\begin{array}{l}-0.669 \\
(0.399)\end{array}$ & $\begin{array}{c}-2.754 * * \\
(0.923)\end{array}$ & $\begin{array}{l}-0.781 \\
(0.630)\end{array}$ \\
\hline PCIt & $\begin{array}{c}0.275 \\
(0.171)\end{array}$ & $\begin{array}{c}0.534 \\
(0.352)\end{array}$ & $\begin{array}{l}0.657^{*} \\
(0.283)\end{array}$ & $\begin{array}{c}0.413 \\
(0.256)\end{array}$ & $\begin{array}{l}1.646 * * \\
(0.502)\end{array}$ & $\begin{array}{l}1.246 * * \\
(0.433)\end{array}$ & $\begin{array}{c}0.769 * * \\
(0.163)\end{array}$ & $\begin{array}{l}0.508 * \\
(0.237)\end{array}$ & $\begin{array}{l}1.245 * * \\
(0.228)\end{array}$ & $\begin{array}{l}-0.516^{*} \\
(0.222)\end{array}$ & $\begin{array}{c}0.033 \\
(0.492)\end{array}$ & $\begin{array}{l}-0.465 \\
(0.333)\end{array}$ \\
\hline
\end{tabular}

Standard errors in parentheses.

Significance: $* * 1 \%, * 5 \%$

$\mathrm{N}=1600$ for each regression. The regressions use robust standard errors, and coefficients of the quarter and state dummy variables are not reported. 


\begin{tabular}{|l|c|c|c|c|c|c|}
\hline \multicolumn{7}{|c|}{ Table 3. Nonlinear RISKSCORE regressions for repeat buyers - 2001Q1 - 2008Q4 } \\
\hline & \multicolumn{2}{|c|}{ Mean } & \multicolumn{2}{c|}{$10^{\text {th }}$ Percentile } & \multicolumn{2}{c|}{$25^{\text {th }}$ Percentile } \\
\hline & $4 \mathrm{Q}$ lag & 2Q lag & 4Q lag & 2Q lag & 4Q lag & NL: 2Q lag \\
\hline Constant & $714.933^{* *}$ & $716.652^{* *}$ & $611.468^{* *}$ & $610.444^{* *}$ & $660.194^{* *}$ & $662.026^{* *}$ \\
& $(7.551)$ & $(8.067)$ & $(14.959)$ & $(15.635)$ & $(12.205)$ & $(13.036)$ \\
\hline$\rho$ & $0.186^{* *}$ & $0.264^{* *}$ & $0.104^{* *}$ & $0.142^{* *}$ & $0.139^{* *}$ & $0.211^{* *}$ \\
& $(0.033)$ & $(0.033)$ & $(0.029)$ & $(0.032)$ & $(0.032)$ & $(0.034)$ \\
\hline HPICHGt-4 & $-0.436^{* *}$ & & $-0.625^{* *}$ & & $-0.637^{* *}$ & \\
$\left(\beta_{1}\right)$ & $(0.046)$ & & $(0.086)$ & & $(0.071)$ & \\
\hline HPICHGt-2 & & $-0.395^{* *}$ & & $-0.501^{* *}$ & & $-0.553^{* *}$ \\
$\left(\beta_{1}\right)$ & & $(0.048)$ & & $(0.086)$ & & $(0.074)$ \\
\hline$C C t$ & $0.082^{* *}$ & $0.073^{* *}$ & $0.219^{* *}$ & $0.196^{* *}$ & $0.145^{* *}$ & $0.129^{* *}$ \\
& $(0.020)$ & $(0.021)$ & $(0.037)$ & $(0.038)$ & $(0.030)$ & $(0.033)$ \\
\hline UNR $t$ & 0.246 & 0.143 & -0.724 & -0.461 & -0.002 & -0.004 \\
& $(0.346)$ & $(0.377)$ & $(0.672)$ & $(0.696)$ & $(0.546)$ & $(0.585)$ \\
\hline PCI $t$ & 0.388 & 0.223 & 0.634 & 0.490 & $0.822^{*}$ & 0.605 \\
& $(0.194)$ & $(0.200)$ & $(0.382)$ & $(0.388)$ & $(0.317)$ & $(0.323)$ \\
\hline
\end{tabular}

Standard errors in parentheses.

Significance: $* * 1 \%, * 5 \%$

$\mathrm{N}=1600$ for each regression. The regressions use robust standard errors, and coefficients of the quarter and state dummy variables are not reported. 
Table 4. Nonlinear RISKSCORE regressions for refinancers - 2001Q1 - 2008Q4

\begin{tabular}{|l|c|c|c|c|c|c|}
\hline & \multicolumn{2}{|c|}{ Mean } & \multicolumn{2}{c|}{$10^{\text {th }}$ Percentile } & \multicolumn{2}{c|}{$25^{\text {th }}$ Percentile } \\
\hline & 4 Q lag & 2Q lag & 4Q lag & 2Q lag & 4Q lag & 2Q lag \\
\hline Constant & $696.735^{* *}$ & $671.574^{* *}$ & $521.663^{* *}$ & $498.200^{* *}$ & $620.935^{* *}$ & $581.994^{* *}$ \\
& $(12.117)$ & $(16.270)$ & $(24.433)$ & $(30.094)$ & $(20.992)$ & $(27.638)$ \\
\hline$\rho$ & $0.505^{* *}$ & $0.612^{* *}$ & $0.412^{* *}$ & $0.557^{* *}$ & $0.555^{* *}$ & $0.663^{* *}$ \\
& $(0.056)$ & $(0.058)$ & $(0.060)$ & $(0.079)$ & $(0.068)$ & $(0.070)$ \\
\hline HPICHGt-4 & $-0.454^{* *}$ & & $-0.687^{* *}$ & & $-0.608^{* *}$ & \\
$\left(\beta_{1}\right)$ & $(0.051)$ & & $(0.118)$ & & $(0.082)$ & \\
\hline HPICHGt-2 & & $-0.464^{* *}$ & & $-0.679^{* *}$ & & $-0.595^{* *}$ \\
$\left(\beta_{1}\right)$ & & $(0.064)$ & & $(0.131)$ & & $(0.102)$ \\
\hline CCt & 0.026 & -0.017 & 0.110 & 0.033 & 0.049 & -0.018 \\
& $(0.036)$ & $(0.034)$ & $(0.065)$ & $(0.067)$ & $(0.064)$ & $(0.058)$ \\
\hline UNRt & $0.991^{*}$ & 0.866 & 1.748 & 1.644 & 1.411 & 1.386 \\
& $(0.500)$ & $(0.483)$ & $(1.060)$ & $(0.993)$ & $(0.832)$ & $(0.829)$ \\
\hline PCI $t$ & $0.847^{* *}$ & $0.840^{*}$ & $2.406^{* *}$ & $2.227^{* *}$ & $1.741^{* *}$ & $1.519^{* *}$ \\
& $(0.309)$ & $(0.354)$ & $(0.632)$ & $(0.660)$ & $(0.492)$ & $(0.566)$ \\
\hline
\end{tabular}

Standard errors in parentheses.

Significance: $* * 1 \%, * 5 \%$

$\mathrm{N}=1600$ for each regression. The regressions use robust standard errors, and coefficients of the quarter and state dummy variables are not reported. 


\begin{tabular}{|l|c|c|c|c|c|c|}
\hline \multicolumn{2}{|c|}{ Table 5. Nonlinear RISKSCORE regressions for first time buyers - 2001Q1-2008Q4 } \\
\hline & \multicolumn{2}{|c|}{ Mean } & \multicolumn{2}{c|}{$10^{\text {th }}$ Percentile } & \multicolumn{2}{c|}{$25^{\text {th }}$ Percentile } \\
\hline & $4 \mathrm{Q}$ lag & 2Q lag & 4Q lag & 2Q lag & 4Q lag & 2Q lag \\
\hline Constant & $663.657^{* *}$ & $658.563^{* *}$ & $564.056^{* *}$ & $561.001^{* *}$ & $592.554^{* *}$ & $583.233^{* *}$ \\
& $(8.140)$ & $(9.104)$ & $(10.899)$ & $(12.103)$ & $(11.176)$ & $(12.331)$ \\
\hline$\rho$ & $0.264^{* *}$ & $0.382^{* *}$ & $0.450^{* *}$ & $0.277^{* *}$ & $0.266^{* *}$ & $0.380^{* *}$ \\
& $(0.031)$ & $(0.036)$ & $(0.030)$ & $(0.035)$ & $(0.033)$ & $(0.037)$ \\
\hline HPICHGt-4 & $-0.149^{* *}$ & & 0.100 & & $-0.176^{* *}$ & \\
$\left(\beta_{1}\right)$ & $(0.044)$ & & $(0.060)$ & & $(0.065)$ & \\
\hline$H P I C H G t-2$ & & $-0.162^{* *}$ & & -0.082 & & $-0.153^{*}$ \\
$\left(\beta_{1}\right)$ & & $(0.044)$ & & $(0.057)$ & & $(0.065)$ \\
\hline$C C_{t}$ & 0.041 & 0.034 & $0.159^{* *}$ & $0.143^{* *}$ & $0.118^{* *}$ & $0.101^{* *}$ \\
& $(0.022)$ & $(0.023)$ & $(0.027)$ & $(0.028)$ & $(0.032)$ & $(0.035)$ \\
\hline UNRt & -0.315 & -0.339 & 0.056 & 0.074 & -0.407 & -0.175 \\
& $(0.279)$ & $(0.327)$ & $(0.389)$ & $(0.455)$ & $(0.375)$ & $(0.431)$ \\
\hline PCI $t$ & $0.790^{* *}$ & $0.796^{* *}$ & $0.525^{*}$ & 0.533 & $1.224^{* *}$ & $1.283^{* *}$ \\
& $(0.194)$ & $(0.221)$ & $(0.263)$ & $(0.292)$ & $(0.269)$ & $(0.299)$ \\
\hline
\end{tabular}

Standard errors in parentheses.

Significance: $* * 1 \%, * 5 \%$

$\mathrm{N}=1600$ for each regression. The regressions use robust standard errors, and coefficients of the quarter and state dummy variables are not reported. 


\begin{tabular}{|l|c|c|c|c|c|c|}
\hline \multicolumn{7}{|c|}{ Table 6. Nonlinear RISKSCORE regressions for investors - 2001Q1 - 2008Q4 } \\
\hline & \multicolumn{2}{|c}{ Mean } & \multicolumn{2}{c|}{$10^{\text {th }}$ Percentile } & \multicolumn{2}{c|}{$25^{\text {th }}$ Percentile } \\
\hline & 4Q lag & 2Q lag & 4Q lag & 2Q lag & 4Q lag & 2Q lag \\
\hline Constant & $765.342^{* *}$ & $755.881^{* *}$ & $670.811^{* *}$ & $657.788^{* *}$ & $734.584^{* *}$ & $721.917^{* *}$ \\
& $(9.861)$ & $(10.987)$ & $(20.458)$ & $(22.343)$ & $(14.626)$ & $(16.191)$ \\
\hline$\rho$ & $0.236^{* *}$ & $0.309^{* *}$ & $0.073^{*}$ & $0.169^{* *}$ & $0.155^{* *}$ & $0.255^{* *}$ \\
& $(0.028)$ & $(0.031)$ & $(0.029)$ & $(0.031)$ & $(0.029)$ & $(0.032)$ \\
\hline HPICHGt-4 & $-0.292^{* *}$ & & $-0.555^{* *}$ & & $-0.466^{* *}$ & \\
$\left(\beta_{1}\right)$ & $(0.040)$ & & $(0.100)$ & & $(0.064)$ & \\
\hline$H P I C H G t-2$ & & $-0.140^{* *}$ & & $-0.315^{* *}$ & & $-0.250^{* *}$ \\
$\left(\beta_{1}\right)$ & & $(0.047)$ & & $(0.107)$ & & $(0.073)$ \\
\hline$C C t$ & 0.003 & -0.019 & 0.089 & 0.044 & 0.042 & -0.001 \\
& $(0.030)$ & $(0.031)$ & $(0.053)$ & $(0.057)$ & $(0.044)$ & $(0.046)$ \\
\hline UNR $t$ & -0.637 & -0.078 & $-2.649^{* *}$ & -1.571 & -0.769 & 0.075 \\
& $(0.422)$ & $(0.466)$ & $(0.949)$ & $(1.023)$ & $(0.657)$ & $(0.726)$ \\
\hline PCI $t$ & -0.382 & -0.297 & 0.094 & 0.232 & -0.409 & -0.262 \\
& $(0.247)$ & $(0.270)$ & $(0.509)$ & $(0.547)$ & $(0.362)$ & $(0.397)$ \\
\hline
\end{tabular}

Standard errors in parentheses.

Significance: $* * 1 \%, * 5 \%$

$\mathrm{N}=1600$ for each regression. The regressions use robust standard errors, and coefficients of the quarter and state dummy variables are not reported. 


\section{References}

Anderson, C.D., Capozza, D.R., Van Order, R., 2011. Deconstructing a mortgage meltdown: A methodology for decomposing underwriting quality. Journal of Money, Credit and Banking 43, 609-631.

Arce, Ó., López-SAlido D., 2011. Housing bubbles. American Economic Journal: Macroeconomics 3, 212-241.

BrueCKneR, J.K., 2000. Mortgage default with asymmetric information. Journal of Real Estate Finance and Economics 20, 251-274.

Case, K.E., ShILler, R.J., 2003. Is there a bubble in the housing market? Brookings Papers on Economic Activity, Fall, 299-342.

Coleman, M., LaCour-Little, M., Vandell, K., 2008. Subprime lending and the housing bubble: Tail wags dog? Journal of Housing Economics 17, 272-290.

Dell'Ariccia, G., Igan, D., Laeven, L., 2008. Credit booms and lending standards: Evidence from the subprime mortgage market. Working paper, International Monetary Fund.

Foote, C.L., Gerardi, K., Willen, P.S., 2008. Negative equity and foreclosure: Theory and evidence. Journal of Urban Economics 64, 234-245.

Glaeser, E.L., Gottlieb J.D., Gyourko, J., Can cheap credit explain the housing boom? NBER working paper \#16230.

Goetzmann, W.N, Peng, Y., Yen, J., 2011. The subprime crisis and house price appreciation. Journal of Real Estate Finance and Economics, in press.

Guiso, L. Sapienza, P., Zingales, L., 2011. The determinants of attitudes towards strategic default on mortgages. Working paper, Chicago Booth School of Business.

Himmelberg, C., Mayer, C., Sinai, T., 2005. Assessing high house prices: Bubbles, fundamentals and misperceptions. Journal of Economic Perspectives 19, 67-92.

IaCOVIEllo M., Neri, S., 2010. Housing market spillovers: Evidence from an estimated DSGE model. American Economic Journal: Macroeconomics 2, 125-164.

Kau, J.B., Keenan, D.C., Kim, T., 1993. Transaction cost, suboptimal termination and default probabilities. Journal of the American Real Estate and Urban Economics Associa- 
tion 21, 247-263.

Kau, J.B., Keenan, D.C., Kim, T., 1994. Default probabilities for mortgages. Journal of Urban Economics 35, 278-296.

Kiyotaki, N., Moore, J., 1997. Credit cycles. Journal of Political Economy 105, 211-248.

Lambertini, L., Mendicino, C., Punzi, M., 2010. Expectations-driven cycles in the housing market. Unpublished paper, Munich Personal RePEc Archive.

Mian, A., Sufi A., 2009. The consequences of mortgage credit expansion: Evidence from the U.S. mortgage default crisis. Quarterly Journal of Economics 124, 1449-1496.

Riddiough, T., Thompson, H.E.. 1993. Commercial mortgage pricing and unobservable borrower default costs. Journal of the American Real Estate and Urban Economics Association 21, 265-291.

Stiglitz, J.E., Weiss, A., 1981. Credit rationing in markets with imperfect information. American Economic Review 71, 393-4120.

Pavlov, A., Wachter, S., 2011. Subprime lending and real estate prices. Real Estate Economics 39, 1-17.

Wheaton, W.C., Nechayev, G., 2008. The 1998-2005 housing "bubble" and the current "correction": What's different this time? Journal of Real Estate Research 30, 1-26. 


\section{Footnotes}

${ }^{*}$ We thank Rainald Borck, Bill Branch, Kangoh Lee, Pierre Picard, Stuart Rosenthal and two referees for helpful comments and suggestions, and we are especially grateful to David Brownstone for econometric advice and to Jason Novak for extensive help with the data. Errors or shortcomings, however, are our responsibility.

${ }^{1}$ Neither Coleman, LaCour-Little and Vandell (2008) nor Glaeser, Gottlieb and Gyourko (2010) find an association between credit supply (the subprime share and loan approval rates, respectively) and price escalation. Wheaton and Nechayev (2008), on the other hand, show that a regression relating prices to economic fundamentals through 1998 under-predicts prices during the subsequent 1998-2005 period. The forecast errors from this regression are larger in MSAs with substantial subprime lending activity, suggesting a connection between such lending and price growth. Pavlov and Wachter (2011) find that regions with a high incidence of subprime and non-traditional credit experienced larger price increases than areas with low concentrations of such lending.

${ }^{2}$ Himmelberg, Mayer and Sinai (2005) argue against the presence of bubble conditions as of 2004 by showing that the user-cost of owner-occupied housing (based on historical appreciation rates) was similar to rent levels across different MSAs. Under bubble conditions, usercost would be far below current rents. Glaeser, Gottlieb and Gyourko (2010) demonstrate that this implication of the standard user-cost model is not robust to incorporating meanreverting interest rates, mobility, prepayment, elastic housing supply, and credit-constrained home buyers. They present an empirical analysis that suggests that low interest rates can explain only one-fifth of the rise in prices from 1996 through 2006, thus arguing that expectations likely played a significant role in generating the housing bubble.

${ }^{3}$ Anderson, Capozza, and Van Order (2011) suggest a variation on this argument, whereby favorable expectations of future credit performance are a consequence of biases in risk models. They argue that when the model calibration period is economically favorable, lenders underestimate default likelihoods "and misjudge the efficacy of their models," while "the opposite occurs when economic conditions are unfavorable."

${ }^{4}$ Instead, Mian and Sufi (2009) conclude that supply factors, including relaxation of underwriting standards and the growth of mortgage securitization, played an important role.

${ }^{5}$ Recent papers in macroeconomics explore the factors that generate price volatility and bubbles in the housing market. Lambertini, Mendicino and Punzi (2010) present an empirical analysis showing a link between expectations and boom-bust housing cycles. Arce and López-Salido (2011) view a housing bubble as an equilibrium where houses are held only for resale (not generating rent or utility) and show that a low downpayment requirement is 
required to sustain such an equilibrium. Iacoveillo and Neri (2010) use a calibrated DSGE model to explore the sources of volatility in house prices. All this work draws on the classic paper of Kiyotaki and Moore (1997), which demonstrated the effect of collateral constraints on the dynamic behavior of the economy.

${ }^{6}$ Using survey data, Guiso, Sapienza and Zingales (2011) provide the first concrete evidence showing that moral attitudes affect the willingness to default. They also show that anger about the economic situation makes default more likely.

${ }^{7}$ For example, moving costs may be an element of $C$ in the absence of a trigger event, while disappearing from $C$ when a trigger event is present, as follows. Without a trigger event that requires a move, moving costs will be zero in the absence of default (in which case the borrower stays in the house), but the cost will be positive with default, in which case a move is required. In this case, moving cost is an element of $C$. Suppose instead that a trigger event such as unemployment occurs. Then, assuming the house becomes unaffordable, the borrower must move regardless of whether default occurs, so that moving costs no longer represent part of default costs. Thus, the trigger event depresses $C$, making default more likely, as seen in the ensuing discussion.

${ }^{8}$ The density $f(P)$ is presumably positive only over a subinterval within $[0, \infty]$, which can be denoted $[\underline{P}, \bar{P}]$. For $(3)$ to be relevant, $B-C$ must lie within this interval. Otherwise, the probability of default is either zero or one.

${ }^{9}$ In particular, borrower price expectations, which currently play no role, would affect the default decision and would thus need to enter the analysis.

${ }^{10}$ The curve is drawn as linear even though other shapes are possible. The same point applies to Figure 2 below.

${ }^{11}$ Stiglitz and Weiss (1981) analyze a model with credit rationing, where all borrowers similarly cannot get a loan. The mechanism is different, however, since borrower riskiness is unobservable. In this setting, a market-clearing increase in the interest rate may reduce lender profits by discouraging less-risky borrowers from applying for loans (making it optimal to leave the rate at a level that elicits excess demand for funds).

${ }^{12}$ The reason is that, since $P_{0}$ is a component of $B$, with the remainder equal to the interest payment, a larger $P_{0}$ would shrink that payment if $\widehat{B}$ were held fixed, pushing it below $\alpha y$. For the interest payment to remain at its maximal level, $\widehat{B}$ must then increase with $P_{0}$.

${ }^{13}$ Negativity follows because $\partial \widehat{B} / \partial P_{0}=1$ and $\pi_{B}<1$. Referring to (6), this latter inequality 
follows because $\eta \leq 1$ and the integral in (6) is less than unity.

${ }^{14}$ It could be argued that the model should include a class of housing investors, who buy houses and resell them for profit in the next period. If investors have the same price expectations as lenders, then the expected return (computed using these expectations) from this activity might equal a fixed riskless return. While this addition would provide another way of pinning down $P_{0}$, investors are omitted from the model on the belief that their role in the singlefamily housing market is small relative to that of owner-occupants.

${ }^{15}$ These conclusions follow because the modified version of (3) is increasing in $B$, decreasing in $P_{0}$, and increasing in $\delta$.

${ }^{16}$ These properties follow from differentiation of (17) and use of the properties of the $\phi$ function.

${ }^{17}$ This property follows because, if $P_{0}^{t-1}$ is increased by an amount $\epsilon$, then $P$ must also be increased by $\epsilon$ to keep the height of the density at its original value.

${ }^{18}$ These borrowers are assumed to reenter the pool of potential mortgage borrowers without penalty. The potential-borrower pool thus consists of the same individuals from period to period, who need a mortgage to repurchase the housing they just relinquished either through sale or default. In reality, borrowers who default enter the rental market for housing, which is suppressed under the current setup. This suppression is not completely unrealistic given that renter status for defaulters is typical temporary, with new mortgages available to them after a few years. Another point is that any capital gains earned upon sale of a house do not affect a borrower's ability to secure another mortgage. By affecting wealth, not income, these gains do not loosen the payment-to-income constraint, and they cannot be used for a downpayment given the assumption of 100 percent loans.

${ }^{19}$ When $\widehat{C}^{t-1}$ increases, $\widehat{C}^{t}$ must increase holding $P_{0}^{t}$ fixed to maintain the equality in (19).

${ }^{20} \widehat{C}^{t-1}=\widehat{C}^{t}$ must hold in the steady state, so that the number of borrowers $1-G(\widehat{C})$ and thus the number of houses is constant over time. From (19), this requirement implies $P_{0}^{t}=$ $P^{*}$, ensuring that housing supply equals zero and that the stock is thus constant. Then, substituting $P_{0}^{t}=P_{0}^{t-1}=P^{*}$ into (18) (along with $\delta=0$ ), the condition yields a steady-state value for $\widehat{C}$, denoted $\widehat{C}^{*}$.

${ }^{21}$ This conclusion follows from computing $\partial P_{0} / \partial \delta=-\pi_{\delta} / \pi_{P_{0}}$ from (18) and showing that it is less than unity. Since the upward shift in the $\pi$ locus is thus less than $\delta$, it follows from Figure 2 that the increase in $P_{0}$ must also be less than $\delta$. In other words, given the negative slope of the $s$-d locus, the increase in $P_{0}$ must be smaller than the vertical shift of the $\pi$ 
locus, which is itself less than $\delta$.

${ }^{22}$ The relation between $\widehat{C}^{\tau+1}$ and $\widehat{C}^{\tau}$ depends on whether $P_{0}^{\tau+1}$ is above or below $P^{*}$. If $P_{0}^{\tau+1}>P^{*}$ holds, then the housing stock is growing, and the number of mortgage borrowers must be rising, implying $\widehat{C}^{\tau+1}<\widehat{C}^{\tau}$, as in Figure 3. If $P_{0}^{\tau+1}<P^{*}$, then the housing stock is shrinking, implying $\widehat{C}^{\tau+1}>\widehat{C}^{\tau}$.

${ }^{23}$ To see this point, recall that the function $\widetilde{C}\left(P, P_{0}, \delta\right)$ from above indicates that the critical $C$ value below which default occurs depends on the realized price $(P)$, last period's price $\left(P_{0}\right)$, and the position of last period's anticipated house-price density, as captured by $\delta$. In the dynamic setting, the critical value $\widetilde{C}^{\tau}$ at time $\tau$ is found by replacing $P$ in this function by $P_{0}^{\tau}, P_{0}$ by $P^{*}$ (the price at $\tau-1$ ), and $\delta$ by $P^{*}$, recognizing that the density position in the previous period is now represented by the lagged price (in this case $P_{0}^{\tau-2}=P^{*}$ ) plus the expectations shift, which is zero at time $\tau-1$. Thus, $\widetilde{C}^{\tau}=\widetilde{C}\left(P_{0}^{\tau}, P^{*}, P^{*}\right)$. By contrast, the steady-state value $\widetilde{C}$ is given by $\widetilde{C}^{*}=\widetilde{C}\left(P^{*}, P^{*}, P^{*}\right)$. Since, from above, $\widetilde{C}$ is decreasing in its first argument, it follows that $\widetilde{C}^{\tau}<\widetilde{C}^{*}$, so that the critical value declines at $\tau$.

${ }^{24}$ The derivative of $D^{t}$ with respect to $\widehat{C}^{t-1}$ has the sign of $G^{\prime}\left(\widehat{C}^{t-1}\right)\left[G\left(\widetilde{C}^{t}\right)-N\right]<0$.

${ }^{25}$ The critical $\widetilde{C}$ value at time $\tau+1$ is given by $\widetilde{C}^{\tau+1}=\widetilde{C}\left(P_{0}^{\tau+1}, P_{0}^{\tau}, P^{*}+\delta\right)$, recognizing that the position of the density at $\tau$ is captured by the lagged price $P_{0}^{\tau-1}=P^{*}$ plus the time- $\tau$ expectations shift. Relative to $\widetilde{C}^{\tau}=\widetilde{C}\left(P_{0}^{\tau}, P^{*}, P^{*}\right)$, the first argument of $\widetilde{C}\left(P_{0}^{\tau+1}, P_{0}^{\tau}, P^{*}+\right.$ $\delta)=\widetilde{C}^{\tau+1}$ is smaller while the second and third are larger. Since $\widetilde{C}$ is increasing in the second argument and decreasing in the others, it follows that the relationship between $\widetilde{C}^{\tau+1}$ and $\widetilde{C}^{\tau}$ is ambiguous.

${ }^{26} \widetilde{C}$ declines slightly between $\tau$ and $\tau+1$, tending to reduce the default rate, but the muchlarger change in $\widehat{C}$ dominates.

${ }^{27} \mathrm{~A}$ further slight decline in $\widetilde{C}$ is offset by a continuing decline in $\widehat{C}$.

${ }^{28}$ If the lender's price expectations are myopic, with $f$ independent of the past price history, it can be shown analytically that convergence back to the steady state is guaranteed. We are indebted to Pierre Picard for this demonstration, which holds in the general version of the model.

${ }^{29} \mathrm{~A}$ relaxation of the payment-to-income constraint (an increase in $\alpha$ ) or a decline in origination costs $k$ leads to a similar adjustment process. But if either of these changes is permanent, the 
steady-state is altered, in contrast to the case of a one-time expectations shock. Either change shifts the $\pi$ locus upward in Figure 3, leading to an initial expansion of subprime lending and an increase in the house price. With the steady state altered in each case, however, convergence to new equilibrium values occurs. The steady-state house price remains at $P^{*}$ given that neither change affects the supply-demand condition (19), but the steady-state value of $\widehat{C}$ falls when $\alpha$ increases or $k$ declines. Therefore, the new steady-state equilibrium reflects a permanent increase in subprime lending and a larger housing stock. Note that since the adjustment process generated by either of these changes involves falling house prices, it will exhibit a temporary surge in defaults like that in Figure 5.

${ }^{30}$ All these quarterly numbers are averages of monthly values.

${ }^{31}$ This evidence comes from regressions of building permits on past price appreciation. Presumably, a large volume of building permits signals optimism about future prices. In a regression of the permit volume in state $j$ and quarter $t$ on past annual price appreciation along with state and quarter fixed effects, the appreciation coefficient is significantly positive. This outcome emerges regardless of whether appreciation is measured through the current quarter or whether the annual appreciation rate is lagged by two or four quarters (being measured through quarter $t-2$ or quarter $t-4)$. Thus, optimism about future prices, as reflected in building permits, appears to be linked to past appreciation.

${ }^{32}$ Note that, among other things, state fixed effects capture interstate differences in lenders' ability to recover their funds upon default, which may affect lending practices (states differ in their use of judicial vs. nonjudicial foreclosure and in the recourse status of mortgages).

${ }^{33}$ This presumption could be reversed by other subtler effects. For example, high unemployment could keep riskier borrowers from even entering the housing market, leading to a positive association between risk scores and this variable. As will be seen below, the unemployment coefficient is almost always insignificant in the regressions, suggesting that such offsetting effects may be at work.

${ }^{34}$ This AR structure can be derived from an underlying process where the autoregressive lag is a single quarter, with $\epsilon_{j t}=\lambda \epsilon_{j t-1}+u_{j t}$, where the $u_{j t}$ are i.i.d. error terms with variance $\sigma^{2}$. Successive substitution yields $\epsilon_{j t}=\rho \epsilon_{j t-4}+v_{j t}$, where $\rho=\lambda^{4}$ and $v_{j t}=u_{j t}+\lambda u_{j t-1}+$ $\lambda^{2} u_{j t-2}+\lambda^{3} u_{j t-3}$. In this case, the $v_{j t}$ 's are correlated, with $E\left(v_{j t}, v_{j t-1}\right)=\left(\lambda+\lambda^{3}+\lambda^{5}\right) \sigma^{2}$, $E\left(v_{j t}, v_{j t-2}\right)=\left(\lambda^{2}+\lambda^{4}\right) \sigma^{2}, E\left(v_{j t}, v_{j t-3}\right)=\lambda^{3} \sigma^{2}$, and $E\left(v_{j t}, v_{j t-k}\right)=0$ for $k>3$. In the case where the HPICHG lag in (21) is two quarters rather than four, $\epsilon_{j t}=\rho \epsilon_{j t-2}+v_{j t}$, where $v_{j t}=u_{j t}+\lambda u_{j t-1}, E\left(v_{j t}, v_{j t-1}\right)=\lambda \sigma^{2}$, and $E\left(v_{j t}, v_{j t-k}\right)=0$ for $k>1$.

${ }^{35}$ Since the main sources of within-state error correlation are removed by the inclusion of state dummies and the use of an autoregressive transformation, the alternative approach of 
clustering at the state level does not appear necessary. Note that when the autoregressive structure is generated by an underlying process with a one-quarter lag, then the error terms $v_{j t}$ in (24) are correlated within each state but in a complex fashion. As seen in footnote 33, when the HPICHG lag in (21) is four quarters, the error correlation is positive when the time index differs by three or less and equals zero otherwise. When the HPICHG lag is two quarters, the error correlation is positive when the time index differs by one and equals zero otherwise. As a result, the error structure does not have the constant error correlation within states that justifies clustering, making robust standard errors more appropriate.

${ }^{36}$ Since the model predicts that more-favorable price expectations should spur lending to the riskiest borrowers, one might expect lagged $H P I C H G$ to have a stronger effect at lower percentiles of the risk-score distribution. A comparison of Table 3's nonlinear four-quarterlag results for the 10th and 25th percentiles confirms this expectation. The elasticity of the 10th percentile risk score with respect to the lagged $H P I C H G$ is more negative than the 25th percentile elasticity, an outcome that can be seen by noting that the larger absolute value of the 25 th percentile $\beta_{1}$ is more than offset by the larger 25 th percentile riskscore in the ratio used to compute the elasticity (see Table 1 ). In contrast, the nonlinear results with a two-quarter lag yield elasticities that are about equal. This outcome suggests that the first elasticity pattern may not be robust, a conclusion that is reinforced below in the case of first-time buyers. The explanation could be that the 25 th percentile risk score already embraces the bulk of subprime borrowers, with impacts at the 10th percentile governed by other considerations.

${ }^{37}$ Letting $g(c)$ denote the density of default costs, the mean $C$ among borrowers getting mortgages is $C_{m} \equiv \int_{\widehat{C}}^{\infty}[C g(C) /(N-G(\widehat{C}))] d C$. In the case of a uniform $g$ with support $[0, \bar{C}]$, $C_{m}=(\widehat{C}+\bar{C}) / 2$, so that the mean drops at half the rate at which $\widehat{C}$ declines, with $\widehat{C}$ conversely dropping at double the rate of the mean. Generally, $\partial C_{m} / \partial \widehat{C}$ equals $\left(C_{m}-\widehat{C}\right)$ times the hazard-rate expression $g(\widehat{C}) /[N-G(\widehat{C})]$. This hazard rate equals $1 /(\bar{C}-\widehat{C})$ in the uniform case, yielding $\partial C_{m} / \partial \widehat{C}<1$, a result that will be strengthened when the hazard rate at $\widehat{C}$ is smaller, as will happen with a unimodal density where $\widehat{C}$ lies below the mode. In such cases, $\partial C_{m} / \partial \widehat{C}$ will be well below one, implying that $\widehat{C}$ drops by a multiple of any measured decline in $C_{m}$.

${ }^{38}$ In contrast to the repeat-buyer and refinancer regressions, the OLS and nonlinear results for first-time buyers and investors have $\beta_{1}$ coefficients of similar size, suggestion no OLS bias.

${ }^{39}$ The $X$ variables in the second-stage equation, (21), are measured at a later time period than those in the first-stage equation, making the analogy to 2SLS imperfect.

${ }^{40}$ The previous discussion suggested that the $Z$ 's would include the growth rates of the $X$ variables along with population growth. Inspection of (23) then shows the first-stage equation 
would contain both the levels and the growth rates of the $X$ 's (which themselves depend on the $X$ levels) along with population growth. Because of this redundancy, the estimated first stage then contains just the $X$ levels and the growth rate of population. Both contemporaneous values and a one-year lag are included. 